\title{
Coupling of integral methods and CFD for modeling complex industrial accidents
}

\author{
Andrea Rum ${ }^{\mathrm{a}}$, Gabriele Landucci ${ }^{\mathrm{a}, *}$, Chiara Galletti ${ }^{\mathrm{a}}$ \\ ${ }^{a}$ Department of Civil and Industrial Engineering, University of Pisa, Italy.
}

\begin{abstract}
Safety enhancement of operations in the chemical and petrochemical industry requires for advances in the tools aimed at supporting risk estimation and evaluation. In conventional risk studies, consequence assessment is carried out through simplified tools and conservative assumptions, often resulting in overestimation of accident severity and worst-case scenarios. Computational Fluid Dynamics (CFD) may overcome the limitation of simplified approaches supporting the study of the dynamic evolution of accidental scenarios and, eventually, the consequences analysis of major accidents. However, the complexity of the problem makes the simulations too computationally demanding; hence an interesting approach is to couple simplified tools based on integral models and CFD. This work is aimed at modeling a safety critical scenario, i.e. domino effect triggered by fire. An integral model is adopted to reproduce a large-scale pool fire, thus simulating the radiative heat received by an exposed pressurized vessel. The behavior of the latter is then modeled through CFD, to investigate the heat-up process and the consequent pressure build up. Potential benefits and limitations of coupling distributed and
\end{abstract}

\footnotetext{
*corresponding author, email: gabriele.landucci@unipi.it
} 
integral models to support consequence assessment studies are discussed. Keywords: Volume Of Fluid, liquid stratification, pool fire, safety, major accident hazard, Computational Fluid Dynamics

\section{Introduction}

2

Safety enhancement of operations in the chemical and petrochemical industry requires for advances in the tools aimed at supporting risk estimation and evaluation. Risk analysisuses engineering and mathematical techniques (Crowl and Louvar (2011)), to evaluate consequences of accidents and thus their potential impact (Mannan (2012) Center of Chemical Process Safety (2000)). As remarked by several authors (e.g., Kalantarnia et al. (2009), Landucci and Paltrinieri (2016)), in the consolidated procedures for quantitative risk assessment (QRA), conservative simplifications and a rather static approach are adopted for the consequence assessment of fires/explosions (I et al. (2009) ) or toxic dispersion and contaminations (Segu et al. (2014)). This is due to the high number of potential scenarios and uncertainties related to accident identification and characterization. However, neglecting the transient and dynamic effects associated with the complex accident evolution may lead to inaccurate estimation of the risk. Updates and implementation of continuously changing quantities, the mitigation effect of safety barriers, and eventually knowledge and evidence on hazard dynamic evolution need to be accounted for a more accurate accident scenario simulation and, thus, for the risk estimation (Villa et al. (2016), Xin et al. (2017), Zarei et al. (2017)). Cascading events represent a critical safety issue characterized by a complex dynamic evolution (Khakzad and Reniers (2015)) and may consti- 
tute high-consequence chains of accidents (Darbra et al. (2010), Reniers and Cozzani (2013)). In case of a cascading effect, a primary accident, such as a fire occurring in a primary unit, propagates to neighboring units triggering secondary accidents in the surrounding plant area, with potential amplification of consequences (Necci et al. (2015)).

Commonly applied approaches for the safety and risk assessment of this type of scenarios are not yet consolidated and are based on strong simplifications. As reported by Alileche et al. (2015), damage and escalation thresholds are commonly applied to identify secondary scenarios, possibly resulting from a domino effect. The results of consequence analysis models, applied to the simulation of primary scenarios, are compared to the threshold values, identifying a maximum credible escalation radius (Cozzani et al. (2007)) and performing a screening of escalation events (Cozzani et al. (2013)). This type of screening is important to assess the credibility and the criticality of different escalation scenarios, but the detailed analysis of critical units requires more advanced tools, such as distributed parameters models.

Computational Fluid Dynamics (CFD) modeling is a consolidated tool to support industrial projects development and was recently adopted in the framework of consequence assessment and safety studies (Schmidt (2012), Landucci et al. (2016b)). The advanced features of CFD models make them a promising tool to support the assessment of complex accidental scenarios, such as three-dimensional pool fires, jet fires and the possible induced cascading events. Such features correspond to: handling complex threedimensional geometries and environments (e.g. Pontiggia et al. (2010), Pontiggia et al. (2011), Derudi et al. (2014)), analyzing turbulent reactive or 
non-reactive flow of compressible or non-compressible fluids (e.g. Ferziger and Peric (2002), Lomax et al. (2002)) and analyzing multi-phase flows. Hence CFD may be used to simulate the thermal load on a process vessel due to an accidental fire (Masum Jujuly et al. (2015)) and to investigate the transient behavior of the stored fluid and structure (Bi et al. (2011), Jang et al. (2015)) during heat-up.

Several studies were aimed at simulating industrial fires through CFD based tools (Chenthil et al. (2015), Singh et al. (2014)). Pool fire modeling through CFD has been extensively carried out since the 90's, determining the potentialities of distributed parameters codes in capturing the effects of bunds, wind profiles and confinement in the determination of flame structure and associated effects (Sinai and Owens (1995)). More recently, Sun et al. (Sun et al. (2015), Sun and Guo (2013)) provided a dynamic LNG pool fire simulation to estimate mitigation through high expansion foam at different burning times. Several authors proposed pool fire simulations to analyze the potential occurrence of cascading events (e.g., Bainbridge and Keltner (1988), Masum Jujuly et al. (2015), Siddapureddy et al. (2016)). However, they focused on the determination of the thermal loads distribution on the outer surface of the vessels engulfed by the flames (Siddapureddy et al. (2016)) or exposed to distant source radiation (Masum Jujuly et al. (2015)), while the complex behavior of the tank lading was not taken into account.

Due to the high turbulence, jet fire modeling is also a challenging task that was addressed in recent years (Ferreira and Vianna (2016), Hooker et al. (2016), Sun et al. (2017), Zhao and Magenes (2016)). Wang et al. (2014) adopted FireFOAM to study the radiation characteristics of hydrogen and 
hydrogen/methane jet fires, capturing the fluctuations in flame length and radiant fraction. Jang et al. (Jang et al. (2015)) simulated a hydrogen jet fire from an accidental leak, determining the dynamic evolution of the flame temperature and shape into a complex three-dimensional layout. A real scale pipe rack was reproduced, determining the flame impact zone as well as the heat radiation profiles. The utilization of CFD to support three-dimensional QRA studies is also documented in other studies (e.g., I et al. (2009)).

The analysis of the transient behavior of tanks exposed to either pool or jet fires was developed since the early 70's by the US Federal Railroad Administration and Transport Canada (Johnson (1998b), Johnson (1998a)). Since then, several studies were undertaken, focusing on the thermal response of LPG tanks exposed to fire (Moodie (1988)). Lumped-parameter models (Aydemir et al. (1988), Beynon et al. (1988), Birk (1989), Dancer and Sallet (1990), Graves (1973), Heymes et al. (2013), Johnson (1998b), JohnSon (1998a), Ramskill (1988), Salzano et al. (2003)) represent the simplest modeling approach to the problem, needing limited computational time and set-up parameters but usually neglecting important complicating phenomena such as the liquid thermal stratification and expansion (Landucci et al. (2016a)).

Distributed parameters models were applied to the assessment of similar problems, e.g. to the analysis of the heat-up of water in pressurized tanks (Gandhi et al. (2013), Han et al. (2009)), of asphalt in cylindrical tanks (Costa et al. (2013)) or cryogenic liquids (Das et al. (2004), Ren et al. (2013), Roh et al. (2013), Wang et al. (2013)) exposed to external heat sources. Some studies were devoted to the analysis of small scale tanks containing 
pressurized hydrogen gas exposed to localized fires, supported by specific experiments (e.g., Zheng et al. (2012), Zheng et al. (2013)). Therefore the experience with CFD tools is limited to the simulation of the dynamic evolution of fluids with physical and chemical features completely different with respect to LPG and, more in general, to pressurized liquefied hydrocarbons. Only recently CFD models were developed to study the effect of fire exposure on LPG tanks. Bi et al. (2011) considered small-scale LPG tanks, whereas Landucci and coworkers (D'Aulisa et al. (2014), Landucci et al. (2016a)) analyzed large-scale LPG vessels. However, the simulation set-up did not allow to model complex fire scenario exposure. In fact, the heat load was derived empirically or from literature, considering only symmetric and homogeneous heat flux conditions. Moreover, the adopted computational discretization only allowed to separately tracing the liquid and vapor phases, imposing the initial filling level and simulating in details the sole evolution of the liquid phase.

Another key issue that may be investigated through distributed parameters code is the structural response of equipment when exposed to fire. In this case, finite elements modeling (FEM) may be applied for the assessment of the mechanical behavior, thus supporting the prediction of failure conditions, as documented in several industrial studies (e.g. Andreev and Harmuth (2003), Feng et al. (2013), Li et al. (2014)). Saldi and Wen (2016) adopted a specific model for the failure assessment of hydrogen cylinders for automotive applications. In the review presented by (Godoy (2016) $)$, the buckling problems of atmospheric tanks under static or quasi-static loads were investigated and specific modeling approaches were discussed considering accidental fire 
exposure. The coupled assessment of the thermal and mechanical response was undertaken for light fuel oil storages (Rebec et al. (2016)) and pressurized gas pipelines (Jang et al. (2015)). In this case, FEM and CFD are adopted to reproduce heat flux exposure conditions and to predict the eventual failure conditions. To the best of our knowledge, this was not undertaken in a coupled way for pressurized tanks. In fact, Landucci et al. (Landucci et al. (2009a), Landucci et al. (2009b), Landucci et al. (2009c)) and Manu et al. (2009) provided detailed examples of the simulation of LPG tanks exposed to fire, in order to estimate the time to failure and to characterize the escalation scenarios. However, in this latter case, the integration of different modeling approaches for the comprehensive characterization of cascading event chains is not yet consolidated.

The present study focuses on the analysis of pressurized vessels exposed to fire. This type of accidental situation may lead to severe cascading events following the catastrophic rupture of vessels. In the case of storage or processing of flammable liquefied gases under pressure, such as propane, butane, propylene, etc., a BLEVE (Boiling Liquid Expanding Vapour Explosion) may pccur (Reid (1979), Venart (1999)), eventually followed by fireball (Abbasi and Abbasi (2007), Maillette and Birk (1996)).

A multi-level approach for the advanced simulation of accident scenarios involving cascading events will be proposed. This is based on coupling advanced boundary condition, based on integral modeling, to distributed parameters modeling. In particular, the work aims at improving a previous CFD model of a pressurised tank described in D'Aulisa et al. (2014) and Landucci et al. (2016a) in order to assess its response in case of complex 
fire exposure conditions. The latter are imposed by simulating the primary fire through integral models available in literature (Mannan (2012), Van Den Bosh and Weterings (2005)) and coupling the results into the CFD model through bespoke subroutines. The potentiality of the novel approach described in Section 2 will be tested through the application to a large-scale case study defined in Section 3, highlighting the computational requirements and main novelties of the present work in Section 4. Results are shown and discussed in Section 5.

\section{Methodology}

The present study focuses on the analysis of cascading events triggered by fire. The sketch of the problem in shown in Figure11. A pressurized vessel exposed to a pool fire receives heat due to radiation and convection, and subsequently heat is transferred by conduction through the vessel wall to the interior, leading to an increase of vapor and liquid temperature and pressure, as described by Moodie (1988). Significant heat dissipation occurs in the liquid with respect to the vapor due to the higher heat transfer coefficient of the liquid phase, which may be one or two orders of magnitude higher than that of the vapor (Aydemir et al. (1988), Birk (1989), Moodie (1988)).

The heat-up of the liquid leads to strong recirculation phenomena, which cause an upward flow of the hot liquid in the boundary layer and a downward flow in the central region of the tank (Birk and Cunningham (1996)). Consequently, a buoyancy-driven flow is induced by density variations, so that a vertical temperature gradient is established inside the tank, i.e. the 
liquid is thermally stratified (see for instance Birk and Cunningham (1996), Shi et al. (2013), D'Aulisa et al. (2014) and references therein). Hence the vapor at the interface is saturated at the temperature of the warmest liquid layer.

In case of non-uniform exposure of the tank to a fire, it may happen that some regions of the vessel receive more heat load than others. This is schematically shown in Figure 1 where in this case the vessel is subjected to high heat load from the right, whereas to small or nearly zero load from the left.

[Figure 1 about here.]

The present work aims at evaluating the non-uniform heat load on a pressurized tank, generated from a distant radiation source (i.e. a pool fire), and at analyzing the effect of such non-uniform load distribution on the vessel response.

In theory a full simulation of the problem would require the modeling of a 3-dimensional pressurized vessel containing a multi-phase flow and exposed to a pool fire, hence to a transient turbulent reactive flow. This would lead to computationally unfeasible simulations because of the large number of equations needed to describe all phenomena (turbulence, reaction, mass and heat inter-phase transfer and radiation), the large number of cells required for a 3-dimensional geometry including both fluid and solid domains as well as the time discretization required for the transient feature of the problem. Indeed to our knowledge all numerical investigations concentrate on either the fire simulation, thus neglecting the behavior of the lading fluid in the target vessel (e.g. Masum Jujuly et al. (2015)), or the multiphase flow inside the tank 
exposed to fire, thus simplifying the treatment of heat exposure conditions (e.g., Bi et al. (2011), D'Aulisa et al. (2014), Landucci et al. (2016a)). Hence, in the present work the problem is decoupled by addressing separately the pool fire modeling and its effect on the pressurized tank. The underlying assumption is that the pool fire is characterized by a timescale much larger than the storage tank dynamics, so that the flame is considered to be at steady state, whereas transient simulations are adopted for the tank. Moreover, since the study is not focused on the pool fire itself but rather on its impact on the target tank, the pool fire is modeled using an integral approach. The idea is indeed similar to that used by Pontiggia et al. (2011) to analyze a major accident from a LPG rail-car rupture in an urban area; in this case an integral model was used to evaluate the LPG release that was incorporated in the CFD dispersion model in the urban area as a source term.

\section{Test Case}

Figure 2 shows the layout considered for the analysis of the case study. In particular, the tank farm of a refinery is adopted as reference installation. The tank farm is constituted by atmospheric and pressurized tanks. In particular, T1 is an atmospheric tank, storing crude oil (assimilated as n-hexane) and T2 is a pressurized vessel storing LPG (assimilated as pure propane). The main features of the tanks are summarized in Table 1. It was then assumed that a failure in T1 leads to a pool fire in the tank catch basin; the pool fire radiation affects $\mathrm{T} 2$ which is located about $20 \mathrm{~m}$ far from the catch basin edge (see Figure 2). 
[Figure 2 about here.]

[Table 1 about here.]

The consequences of the pool fire in T1 catch basin were evaluated using conventional literature integral models based on surface emissive power approximation, as described by Mannan (2012) and Van Den Bosh and Weterings (2005). A single set of meteorological parameters was used to calculate the consequences of the pool fire, in particular:

- wind velocity $=5 \mathrm{~m} / \mathrm{s}$

- atmospheric neutral conditions (stability class D)

- relative humidity $=50 \%$

- ambient temperature $=20^{\circ} \mathrm{C}$

A uniform wind direction was assumed for the sake of simplicity (see Figure 2), the flame was considered to be stable and in steady state conditions. More details on the calculation procedure for the pool fire consequences are summarized in Appendix A. Pool fire radiation simulation allowed gathering non-uniform boundary conditions for the analysis of the heat-up of target T2 through the CFD model, thus providing an example of coupling different kind of models. For the sake of comparison, the same vessel was simulated assuming a uniform incoming heat radiation distribution, as carried out in conventional literature approaches (D'Aulisa et al. (2014), Landucci et al. (2016a)). 


\section{CFD Model}

\subsection{Computational Domain and Grid}

Since the storage tank has a length much larger, i.e. more than six times, than its diameter, a 2-dimensional (2D) domain corresponding to a cross section of the T2 tank was chosen. This approach was aimed at reducing computational efforts even though some end effects may alter the boundary layer and the warm top layer of the liquid, affecting the pressurization rate. The grid was generated with the O-grid method using the ICEM software, by ANSYS Inc. and, hence, it is block structured. The grid is uniform over all the domain, except near the wall where a refinement was applied to better capture velocity profiles.

The number of cells is 268k and it is extremely large considered the simplicity and 2D feature of the domain; however such a fine grid was found to be necessary to capture the liquid level rise due to the temperature increase in the storage tank. This is one of the main improvements with respect to other works in literature (Bi et al. (2011), D'Aulisa et al. (2014), Landucci et al. (2016a) ), where the grid is refined near the liquid-vapor interface, that is known a priori, in order avoid any convergence problems due to the evaporation/condensation phenomena. In other approaches, the domain is divided into two sub-domains, one for the liquid and one for the vapor phase, as done by D'Aulisa et al. (2014). In such a manner the grid can be coarse, with a significant saving of CPU time; however the change of liquid level due heat-up cannot be predicted effectively. Logically, also in this case the computational grid is suited only for a given initial liquid level.

Instead, the approach of the present work aims at capturing the liquid level 
rise for any initial filling level, through the adoption of the same computational grid. For sake of brevity, results are shown just for a single filling level.

\subsection{Physical Model}

The physical model was based on the Volume of Fluid (VOF) approach that enables the prediction of multi-phase flows in which the interfaces are clearly identified (Hirt and Nichols (1981))

The model assumes that the each control volume contains just one phase or the interface between the phases. This is determined by the volume fraction $\alpha_{L}$ of, say, the liquid phase, identifying three cases:

- if $\alpha_{L}=0$ the cell is completely full of vapor;

- if $\alpha_{L}=1$ the cell is completely full of liquid;

- if $0<\alpha_{L}<1$ the cell contains the vapor-liquid interface.

In presence of a turbulent flow, the governing equations that are solved in the domain are:

- continuity equation

$$
\frac{\partial \rho}{\partial t}+\nabla \cdot(\rho \mathbf{U})=0
$$

- momentum equation

$$
\frac{\partial(\rho \mathbf{U})}{\partial t}+\nabla \cdot(\rho \mathbf{U U})=-\nabla P+\nabla \cdot\left(\mu+\mu_{T}\right)\left(\nabla \mathbf{U}+\nabla \mathbf{U}^{T}\right)+\mathbf{F}
$$

- energy equation

$$
\frac{\partial\left(\rho c_{p} T\right)}{\partial t}+\nabla \cdot\left[\mathbf{U}\left(\rho c_{p} T+P\right)\right]=\nabla \cdot\left[\left(\kappa+\frac{c_{p} \mu_{T}}{P r_{T}}\right) \nabla T\right]+S_{h}
$$


293

294

293

where $\mathbf{U}, T$ and $P$ are the mean velocity vector, temperature and pressure, respectively, and the superscript $T$ indicates the transpose of a vector. $\mu_{T}$ and $P r_{T}$ are the turbulent viscosity and Prandtl number, respectively. The former is determined through the standard $\kappa_{\varepsilon}$ turbulence model with scalable wall functions, whereas the $\operatorname{Pr}_{T}=0.85$ (Tu et al. (2013)).

The properties appearing in the transport equations are determined by the presence of the component phases in each control volume. For instance, density, specific heat and thermal conductivity are computed by the following expressions:

$$
\rho=\alpha_{L} \rho_{L}+\left(1-\alpha_{L}\right) \rho_{V}
$$

$$
c_{p}=\alpha_{L} c_{p L}+\left(1-\alpha_{L}\right) c_{p V}
$$

$$
\kappa=\alpha_{L} \kappa_{L}+\left(1-\alpha_{L}\right) \kappa_{V}
$$

The liquid was modeled as incompressible; even though its density was allowed to vary with temperature in the body force term $\mathbf{F}$ of the momentum equation using the Boussinesq model:

$$
\mathbf{F}=\left(\rho-\rho_{0}\right) \mathbf{g} \approx-\rho_{0} \beta_{T}\left(T-T_{0}\right) \mathbf{g}
$$

where $\rho_{0}$ is the constant density of the fluid, $\beta_{T}$ is the thermal expansion and $T_{0}$ is the operating temperature. No momentum exchange between the liquid and the vapor phase due to surface tension $\sigma$ is considered because it is less important than the gravitational body force, i.e. the Eotvos number $E O=\frac{\left(\rho_{L}-\rho_{v}\right) g L^{2}}{\sigma} \gg 1$, where $L$ is the characteristic length. Therefore, the interface between liquid and vapor can be considered waveless. 
The evolution of the vapor-liquid interface was tracked by solving a a volume fraction continuity equation for each phase except for the primary phase. In this case, setting the vapor phase as a primary phase, the volume fraction continuity equation is solved only for the secondary phase, i.e. the liquid phase. All other equations (momentum, energy, radiation) are shared by the phases. For the liquid phase, the volume fraction continuity equation is:

$$
\frac{\partial\left(\alpha_{L} \rho_{L}\right)}{\partial t}+\nabla \cdot\left(\alpha_{L} \rho_{L} \mathbf{U}\right)=S_{\alpha_{L}}+\left(\dot{m}_{V L}-\dot{m}_{L V}\right)
$$

while for the vapor phase, the volume fraction in each cell is computed following the mathematical constraint:

$$
\alpha_{L}+\alpha_{V}=1
$$

in each cell. In Equation $8 S_{\alpha_{L}}$ represents the rate of increase of liquid volume fraction due to external liquid mass source term (that is zero in the present closed case), whereas $\dot{m}_{V L}-\dot{m}_{L V}$ is the rate of increase of liquid mass due to the difference between the mass transfer from vapor to liquid phase minus the mass transfer from liquid to vapor phase. To simulate in detail the evaporation/condensation phenomenon, hence to determine $\dot{m}_{V L}$ and/or $\dot{m}_{L V}$ the "Lee Model"was adopted (Lee (1980)). The model assumes that the mass is transferred at constant pressure and at quasi thermo-equilibrium state, so that the mass transfer can be estimated (for evaporation, ie for $T>T_{\text {sat }}$ as:

$$
\dot{m}_{L V}-\dot{m}_{V L}=r_{i} \alpha_{L} \rho_{L} \frac{T-T_{s a t}}{T_{s a t}}
$$

where $T_{\text {sat }}$ is the saturation temperature at the given pressure, and $r_{i}$ in the mass transfer intensity factor that was taken $r_{i}=0.1 \mathrm{~s}^{-1}$ as suggested by 
De Schepper et al. (2009) for the simulation of boiling from hydrocarbon feedstock.

For what concern the energy balance and the estimation of the heat transfer during the evaporation or condensation process, only one expression is required, in which the energy source terms related to evaporation $\left(S_{h, \text { evap }} h\right)$ and condensation $\left(S_{h, c o n d} h\right)$ are expressed through the latent heat of vaporization $\lambda_{0}$, for instance:

$$
S_{h, e v a p}=\dot{m}_{L V} \lambda_{0}
$$

Radiation was modeled through the Surface to Surface (S2S) Model, that accounts for the radiation exchange in an enclosure of gray-diffuse surfaces through view factors and neglects any absorption, emission, or scattering. Hence the fluid was considered to not participate to radiation; this is motivated by the low vapor temperature (lower than $400 K$ ). Moreover the S2S model is computationally less demanding than other models such as the Discrete Order, P-n approximation, Discrete Transfer and Monte Carlo method, that involve the calculation of the interaction with the participating medium and ray or photon tracing techniques (Modest (2003)).

\subsection{Physical Properties}

The LPG stored in the vessels exposed to the fire is a mixture of propane and butane, with high propane mass fraction (i.e. 95-98\%). Hence, in the CFD model the LPG is assumed to be pure propane, thus neglecting the presence of heavier components. The saturation temperature $T_{\text {sat }}(\mathrm{K})$ and the latent heat of vaporization $\lambda_{0}\left(\mathrm{~J} \mathrm{~kg}^{-} 1\right)$ are expressed as a function of the absolute pressure $P(\mathrm{~Pa})$, which changes with time, through polynomial 
347

relationship as made by D'Aulisa et al. (2014).

$$
\lambda_{0}=0.0682 P+403262
$$

348 and

$$
T_{\text {sat }}=-6.0 \cdot 10^{-12} P^{2}+5.0 \cdot 10^{-5} P+253.76
$$

349

[Table 2 about here.]

Since the fluid in storage condition and during the exposure to fire is at considerable pressure (more than 10 bar), the Peng Robinson equation of state (PR-EOS) was used to estimate the vapor density:

$$
P=\frac{R T}{v_{m}-b_{P R}}-\frac{a_{P R} \psi(T)}{v_{m}^{2}+2 b_{P R} v_{m}-b_{P R}^{2}}
$$

where $P$ is expressed in bar. In the above expression:

- $R=83.144 \mathrm{~cm}^{3}$ bar $/ \mathrm{mol} \mathrm{K}$

- $a_{P R}=0.45724 \frac{R^{2} T_{c}^{2}}{P_{C}} \mathrm{~cm}^{6} \mathrm{bar} / \mathrm{mol}^{2}$;

$360 \quad \bullet b_{P R}=0.0778 \frac{R T_{C}}{P_{C}} \mathrm{~cm}^{3} / \mathrm{mol}$

361 $\bullet \psi(T)=1+\left(0.37464+1.54226 \omega-0.26992 \omega^{2}\right)\left[1-\left(\frac{T}{T_{C}}\right)^{2}\right]$ 
The critical temperature and pressure for propane are $T_{C}=369.9 \mathrm{~K}$ and $P_{C}=42.051$ bar, respectively, whereas the acentric factor $\omega=0.152$. A detailed validation of the physical model is reported in the work of (D'Aulisa et al. (2014)).

\subsection{Integral Method for Heat Radiation}

In order to estimate the heat flux conditions affecting the tank exposed to fire, an integral model for pool fire radiation simulation was adopted. This allowed determining the heat flux conditions summarized in Section 4.5. The procedure for the consequence assessment of pool fire radiation through integral models is well known in the literature and extended details are reported elsewhere (Mannan (2012), Van Den Bosh and Weterings (2005)). Figure 3 summarizes the procedure adopted in the present study for simulation of

pool fire radiation and the main equations involved. For the sake of brevity, more details on the calculation procedure are discussed in Appendix A.

[Figure 3 about here.]

\subsection{Boundary Conditions}

Two different types of boundary conditions were applied to the tank walls.

- non-uniform heat flux, corresponding to the incident radiation evaluated with the integral model for pool fire, as described in Appendix A. The variation of incident flux with the angular coordinate of the tank wall is shown in Figure 4. It can be observed a maximum radiation of $77 \mathrm{kw} / \mathrm{m}^{2}$ at $45^{\circ}$. Between $90^{\circ}$ and $150^{\circ}$ still some radiation exists, whereas negligible incident heat flux is between $150^{\circ}$ and $270^{\circ}$; 
- uniform heat flux of $26.2 \mathrm{~kW} / \mathrm{m}^{2}$ was applied at the walls. Such value was obtained by averaging the heat radiation distribution predicted by the pool fire model.

The former boundary condition was set through a $\mathrm{C}++$ subroutines described in Appendix A. It is worth noting that, since the boundary conditions consisted of heat flux value, the wall thickness was not specified. However, the approach may be easily extended by adding solid domains for the walls in case an accurate estimation of temperature profiles inside the walls is required, as for instance for the analysis of fireproofing performance (Landucci et al. $(2009 \mathrm{~b}))$.

[Figure 4 about here.]

\subsection{Solver}

A pressure based solver with an implicit time advancement, available in Fluent v. 16, by Ansys Inc., was employed. The time step was chosen in order to ensure a Courant number lower than 5. A first order upwind discretization scheme was used for all equations and the SIMPLE algorithm was applied for the pressure-velocity coupling. Normalized residuals for all equations were typically well below $10^{-6}$. One hour of CPU time was needed to cover $1 \mathrm{~s}$ of real time when run on 32 threads. Simulations were run to cover the time up to tank pressurization corresponding to the set pressure of the release valve (see Table 1). Hence, a single simulation took more than 1 week.

\section{Results and Discussion}

Figure 5 illustrates the distribution of temperature in the liquid phase at different times predicted using an uniform heat flux distribution at the 
walls. It can be observed a mirror-symmetric pattern with respect to the vertical tank mid-plane. The high temperature region evolves from the walls (see the snapshot at time $\tau=5 \mathrm{~s}$ ) towards the liquid surface and then it enters $(\tau=15 \mathrm{~s})$ in the middle to extend downwards. Subsequently, the low temperature region progressively moves to the bottom, leading to a thermal stratification. The liquid level rises of approximately $0.1 \mathrm{~m}$ in $292 \mathrm{~s}$.

The motion originated from the temperature gradients is depicted at the same time steps in Figure 6. At $\tau=5 \mathrm{~s}$ the high velocity regions are located near the wall, where an upward motion is established due to buoyancy effects. It is worthy to remind that no slip velocity is set to the wall; however, the boundary layer thickness is so small (i.e., less than a few millimeters) that the region in which velocity goes from the bulk value to zero is not discernible. The magnitude of the convective velocity $V_{c}$ can be roughly estimated by balancing inertial and buoyancy forces, so that the Grashof number, Gr, can be interpreted as the square of the Reynolds number, Re (Mauri (2015)).

$$
G r=\frac{L^{3} g \beta_{T} \Delta T}{\nu^{2}}=\left(\frac{V_{c} L}{\nu}\right)^{2}=R e^{2}
$$

where $\Delta T$ is the temperature difference driving natural convection, $L$ is the characteristic length and $\nu$ is the kinematic viscosity. Hence $V_{c}$ is proportional to $\sqrt{G r}$ and hence to $\sqrt{\Delta T}$.

Small vortical structures are observed near the liquid-vapor interface very close the walls. Then, such structures increase and move towards the vessel mid-plane, as shown at $\tau=15 \mathrm{~s}$ when a pair of counter-rotating recirculation regions is well evident. These promote the motion of the fluid near the vessel mid-plane towards the bottom, with a velocity of about $0.3 \mathrm{~m} / \mathrm{s}$. The flow is fully turbulent; since the viscosity of propane is low (around $10^{-4} \mathrm{~Pa} \mathrm{~s}$ ) 
the resulting $R e$ is above $10^{5}$ by taking the average velocity across the liquid phase (i.e. $0.08 \mathrm{~m} / \mathrm{s}$ at $\tau=15 \mathrm{~s}$ ) and the characteristic length equal to $1 / 10$ of the tank diameter. The induced turbulent fluctuations, that can be estimated from the turbulent kinetic energy, can result in a turbulent intensity above $10 \%$ in some regions fo the tank.

Subsequently, the strength of the vortical structures progressively diminishes due to mixing that smooths temperature gradients, thus reducing the Grashof number and hence $V_{c}$, finally leading to the thermal stratification depicted in Figure $5 \mathrm{f}$.

In Figure 6c the flow appears slightly asymmetric in the low velocity region near the vessel bottom. In fact, despite the geometry and boundary conditions are symmetric, the flow can be asymmetric due to the establishment of vortical structures, that are more likely promoted in the present unsteady conditions.

[Figure 5 about here.]

[Figure 6 about here.]

Similarly, Figure 7 shows the contours of temperature in the liquid phase at different times, as evaluated using the non-uniform heat flux distribution predicted through the integral model, described in Appendix A. For sake of comparison, the sampling times are the same as those used in Figure 5 , except for the last that refers to opening of the release valve.

It clearly appears the asymmetric feature of the distribution, with the high temperature region originating from the right side (exposed to the fire) and spreading on the top ( $\sec \tau=15 \mathrm{~s}$ ), then moving towards the bottom on the 
479

left side (not exposed to the fire). This is confirmed in Figure 8 that shows, for the same time, a single vortical structure that promotes a descending motion on the left side of the tank.

Subsequently, thermal stratification can be also observed, however with different features. In fact at the same time, the bulk temperature estimated with uniform heat flux conditions is higher than that obtained with the nonuniform ones. In the uniform case the fluid motion is very effective as it comes from both sides on the tank; this promotes the overall heat-up of the lading. Conversely, in the non-uniform case, the fluid motion is unable to affect all the lading as it comes from just one side of the tank; hence the heat-up process is slower than for the uniform case (compare Figure 5 and $7 \mathrm{f})$.

After $\tau=200 \mathrm{~s}$ the asymmetry of the temperature distribution in the nonuniform heat flux is less visible with respect to the initial times due to the weaker motion induced by the lower $G r$.

It is worthy to notice that since the final time is imposed as the one corresponding to the safety valve opening, the temperature at the liquid-vapor interface, which drives the pressure (see Section 2), is the same for the two cases. However, due to the reduced recirculation observed for the nonuniform heat flux case, the upper liquid layer tends to heat-up faster than for the uniform case.

[Figure 7 about here.]

[Figure 8 about here.] 
Subsequently the pressure build up is quicker in the non-uniform heat flux case as also reported in Figure 9a. Such pressure represents an average over the vapor phase, even though the observed differences between different locations in the vapor were less than $0.02 \%$. The release valve pressure opening is predicted after $230 \mathrm{~s}$ for the non-uniform heat flux case, and after $292 \mathrm{~s}$ for the uniform one. Therefore using a more sophisticated approach, despite the large computational and setup efforts, leads to results that are significantly different from the simple uniform heat flux impacting on the tank. In particular, this latter assumption leads to an overestimation of about $30 \%$ of the pressurization time, thus leading to a less conservative prediction. Figure $9 \mathrm{~b}$ shows the evaporation rate, evaluated from the time derivative of the liquid mass, as a function of time for both uniform and non-uniform heat flux. The evaporation rate is similar up to approximately $\tau=100$; subsequently it is larger for uniform than for non-uniform heat flux. This may be imputed to the dependence of latent heat on pressure, reported in Equation 12. Such latent heat is evaluated as a function of time for both cases in Figure 9; after $\tau \approx 100 \mathrm{~s}$ the latent heat for non-uniform heat flux is higher than for uniform heat flux, so that less LPG evaporates for a given heat flux.

\section{Conclusions}

[Figure 9 about here.]

Safety enhancement of chemical and process plants asks for innovative tools in order to support QRA studies. In particular, in order to capture the 
transient and dynamic nature of complex accident scenarios such as cascading events triggered by fire, specific methods are needed to obtain accurate predictions. The present study coupled integral and distributed parameters models to simulate cascading events triggered by fire. In particular, CFD modeling of a pressurized vessel exposed to fire was carried out by imposing heat flux conditions at the walls derived from an integral model for pool fire radiation simulation.

The application to a case study of industrial interest allowed obtaining results that are hardly derivable with simplified models and assumptions and which may be interpreted in a dual perspective. In fact, the simulation of tanks exposed to realistic heat source types allowed determining the influence of the induced buoyancy driven flow on the pressurization rate, thus supporting the investigation of complex stratification and recirculation phenomena. Then, the results showed the influence of realistic fire scenarios on the dynamic evolution of the heat-up of potential target vessels, thus gathering key information about the possible timing for the deployment of emergency teams and resources.

Moreover, the present simulation approach may be extended to vessels containing different types of substances, featuring different operative conditions and geometries. This may allow to gather an extended data set of vessels response during fire exposure, thus supporting the development of vulnerability models for process equipment exposed to fire, such as probit functions (e.g., see Landucci et al. (2009a) for more details). Finally, it is worth mentioning that the computational and setup efforts make unfeasible to extend the approach to all plant sections, so that the most critical ones should be 
530

previously selected through screening criteria (Cozzani et al. (2007)).

\section{References}

Abbasi, T., Abbasi, S., 2007. Accidental risk of superheated liquids and a framework for predicting the superheat limit. Journal of Loss Prevention in the Process Industries 20, 165-181.

Alileche, N., Cozzani, V., Reniers, G., Estel, L., 2015. Thresholds for domino effects and safety distances in the process industry: A review of approaches and regulations. Reliability Engineering and System Safety 143, $74-84$.

Andreev, K., Harmuth, H., 2003. FEM simulation of the thermo-mechanical behaviour and failure of refractories - a case study. Journal of Materials Processing Technology 143-144, 72-77.

Aydemir, N.U., Magapu, V., Sousa, A., Venart, J., 1988. Thermal response analysis of lpg tanks exposed to fire. Journal of Hazardous Materials 20, $239-262$.

Bainbridge, B.L., Keltner, N.R., 1988. Heat transfer to large objects in large pool fires. Journal of Hazardous Materials 20, 21-40.

Beynon, G.V., Cowley, L.T., Small, L.M., Williams, I., 1988. Fire engulfment of LPG tanks: HEATUP, a predictive model. Journal of Hazardous Materials 20, 227-238.

Bi, M.S., Ren, J.J., Zhao, B., Che, W., 2011. Effect of fire engulfment on thermal response of LPG tanks. Journal of Hazardous Materials 192, 874 $-879$. 
Birk, A., 1989. Modelling the effects of a torch-type fire impingement on a rail or highway tanker. Fire Safety Journal 15, 277-296.

Birk, A.M., Cunningham, M.H., 1996. Liquid temperature stratification and its effect on BLEVEs and their hazards. Journal of Hazardous Materials $48,219-237$.

Center of Chemical Process Safety, C., 2000. Guideline for chemical process quantitative risk analysis. American Institute of Chemical Engineers Center of Chemical Process Safety, New York, NY.

Chenthil, K.K., Anil, K.K.R., Tripathi, A., 2015. A unified 3D CFD model for jet and pool fires, in: Institution of Chemical Engineers Symposium Series.

Costa, C.A.S., Mantelli, M.B.H., Milanese, F.H., da Silva, A.K., Rucker, C., Furlan, L.T., 2013. Experimental and numerical study of an asphalt storage tank in a reduced scale. Applied Thermal Engineering 56, 101-109.

Cozzani, V., Tugnoli, A., Bonvicini, S., Salzano, E., 2013. 9 - thresholdbased approach, in: Reniers, G., Cozzani, V. (Eds.), Domino Effects in the Process Industries. Elsevier, Amsterdam, pp. 189 - 207.

Cozzani, V., Tugnoli, A., Salzano, E., 2007. Prevention of domino effect: From active and passive strategies to inherently safer design. Journal of Hazardous Materials 139, $209-219$.

Crowl, D., Louvar, J., 2011. Chemical process safety: Fundamentals with applications. 3rd ed. ed., Prentice Hall PTR, New Jersey. 
Dancer, D., Sallet, D.W., 1990. Pressure and temperature response of liquefied gases in containers and pressure vessels which are subjected to accidental heat input. Journal of Hazardous Materials 25, 3 - 18.

Darbra, R., Palacios, A., Casal, J., 2010. Domino effect in chemical accidents: Main features and accident sequences. Journal of Hazardous Materials 183, $565-573$.

Das, S.P., Chakraborty, S., Dutta, P., 2004. Studies on thermal stratification phenomenon in LH2 storage vessel. Heat Transfer Engineering 25, 54-66.

D’Aulisa, A., Tugnoli, A., Cozzani, V., Landucci, G., A.M., 2014. CFD modeling of LPG vessels under fire exposure conditions. AIChE Journal 60, 4292-4305.

De Schepper, S., Heynderickx, G., Marin, G., 2009. Modeling the evaporation of a hydrocarbon feedstock in the convection section of a steam cracker. Computers and Chemical Engineering 33, 122-132.

Derudi, M., Bovolenta, D., Busini, V., Rota, R., 2014. Heavy gas dispersion in presence of large obstacles: Selection of modeling tools. Industrial and Engineering Chemistry Research 53, 9303-9310.

Feng, S.Z., Cui, X.Y., Li, G.Y., 2013. Analysis of transient thermo-elastic problems using edge-based smoothed finite element method. International Journal of Thermal Sciences 65, 127-135.

Ferreira, E.S., Vianna, S.S.V., 2016. Large eddy simulation combined with equivalent diameter for turbulent jet modelling and gas dispersion. Brazilian Journal of Chemical Engineering 33, 525-540. 
Ferziger, J., Peric, M., 2002. Computational methods for fluid dynamics. Springer-Verlag, Berlin, Germany.

Gandhi, M.S., Joshi, J.B., Vijayan, P.K., 2013. Study of two phase thermal stratification in cylindrical vessels: CFD simulations and PIV measurements. Chemical Engineering Science 98, 125-151.

Godoy, L.A., 2016. Buckling of vertical oil storage steel tanks: Review of static buckling studies. Thin-Walled Structures 103, 1-21.

Graves, K., 1973. Development of a computer model for modeling the heat effects on a tank car (Report FRA-OR\&D 75-33). US Department of Transportation, Federal Railroad Administration, Washington DC.

Green, D., Perry, R., 2008. Perry's Chemical Engineers' Handbook. 8th ed. ed., McGraw - Hill, New York, NY.

Han, Y.M., Wang, R.Z., Dai, Y.J., 2009. Thermal stratification within the water tank. Renewable and Sustainable Energy Reviews 13, 1014-1026.

Heymes, F., Aprin, L., Birk, A.M., Slangen, P., Jarry, J.B., François, H., 2013. An experimental study of an LPG tank at low filling level heated by a remote wall fire. Journal of Loss Prevention in the Process Industries 26, 1484-1491.

Hirt, C., Nichols, B., 1981. Volume of fluid (VOF) method for the dynamics of free boundaries. Journal of Computational Physics 39, $201-225$.

Hooker, P., Hall, J., Hoyes, J.R., Newton, A., Willoughby, D., 2016. Hydro- 
gen jet fires in a passively ventilated enclosure. International Journal of Hydrogen Energy .

I, Y.P., Shu, C.M., Chong, C.H., 2009. Applications of 3D QRA technique to the fire/explosion simulation and hazard mitigation within a naphthacracking plant. Journal of Loss Prevention in the Process Industries 22, 506-515.

Jang, C.B., Choi, S.W., Baek, J.B., 2015. CFD modeling and fire damage analysis of jet fire on hydrogen pipeline in a pipe rack structure. International Journal of Hydrogen Energy 40, 15760-15772.

Johnson, M., 1998a. Tank car thermal analysis, volume 1, user's manual for analysis program, DOT/FRA/ORD-98/09A. Department of Transportation, Federal Railroad Administration, Washington DC.

Johnson, M.R., 1998b. Tank car thermal analysis, volume 2, technical documentation report for analysis program, DOT/FRA/ORD-98/09B. US Department of Transportation, Federal Railroad Administration, Washington DC.

Kalantarnia, M., Khan, F., Hawboldt, K., 2009. Dynamic risk assessment using failure assessment and bayesian theory. Journal of Loss Prevention in the Process Industries 22, 600-606.

Khakzad, N., Reniers, G., 2015. Using graph theory to analyze the vulnerability of process plants in the context of cascading effects. Reliability Engineering and System Safety 143, 63 - 73. 
Landucci, G., D’Aulisa, A., Tugnoli, A., Cozzani, V., Birk, A.M., 2016a. Modeling heat transfer and pressure build-up in LPG vessels exposed to fires. International Journal of Thermal Sciences 104, 228 - 244.

Landucci, G., Gubinelli, G., Antonioni, G., Cozzani, V., 2009a. The assessment of the damage probability of storage tanks in domino events triggered by fire. Accident; analysis and prevention 41, 1206-15.

Landucci, G., Molag, M., Cozzani, V., 2009b. Modeling the performance of coated LPG tanks engulfed in fires. Journal of Hazardous Materials 172, $447-456$.

Landucci, G., Molag, M., Reinders, J., Cozzani, V., 2009c. Experimental and analytical investigation of thermal coating effectiveness for $3 \mathrm{~m} 3 \mathrm{lpg}$ tanks engulfed by fire. Journal of Hazardous Materials 161, 1182-92.

Landucci, G., Paltrinieri, N., 2016. A methodology for frequency tailorization dedicated to the oil \& gas sector. Process Safety and Environmental Protection 104, Part A, 123 - 141.

Landucci, G., Pontiggia, M., Paltrinieri, N., Cozzani, V., 2016b. Chapter 10 - computational fluid dynamics modeling: Tutorial and examples, in: Paltrinieri, N., , Khan, F. (Eds.), Dynamic Risk Analysis in the Chemical and Petroleum Industry. Butterworth-Heinemann, pp. 115 - 125.

Lee, W., 1980. A pressure iteration scheme for two-phase flow modeling. Hemisphere Publishing, Washington, DC. In T.N. Veziroglu (Ed.), Multiphase Transport Fundamentals, Reactor Safety, Applications. 
Li, M.J., Pan, J.H., Ni, M.J., Zhang, N.M., 2014. Heat transfer and thermal stress analysis in fluid-structure coupled field. Applied Thermal Engineering 88, 473-479.

Liley, P., Thomson, G.H.. Friend, D., Daubert, T., Buck, E., De Schepper, S., Heynderickx, G., Marin, G., 1999. Physical and chemical data, Section 2. McGraw - Hill, New York, NY. In: Perrys Chemical Engineers Handbook.

Lomax, H., Pulliam, T., Zingg, D., Kowalewski, T., 2002. Fundamentals of Computational Fluid Dynamics. Springer Verlag, Berlin.

Maillette, J., Birk, A.M., 1996. Influence of release conditions on bleve fireballs, in: American Society of Mechanical Engineers, Pressure Vessels and Piping Division (Publication) PVP, pp. 147-152.

Mannan, S., 2012. Lees Loss Prevention in the Process Industries. 4th ed. ed., Butterworth - Heinemann, Oxford, UK.

Manu, C.C., Birk, A.M., Kim, I.Y., 2009. Stress rupture predictions of pressure vessels exposed to fully engulfing and local impingement accidental fire heat loads. Engineering Failure Analysis 16, 1141-1152.

Masum Jujuly, M., Rahman, A., Ahmed, S., Khan, F., 2015. LNG pool fire simulation for domino effect analysis. Reliability Engineering and System Safety $143,19-29$.

Mauri, R., 2015. Transport Phenomena in Multiphase Flows. Springer International Publishing, Switzerland.

Modest, M., 2003. Radiative Heat Transfer. Academic Press, New York, NY. 
Moodie, K., 1988. Experiments and modelling: an overview with particular reference to fire engulfment. Journal of Hazardous Materials 20, 149-175.

Necci, A., Cozzani, V., Spadoni, G., Khan, F., 2015. Assessment of domino effect: State of the art and research needs. Reliability Engineering and System Safety 143, $3-18$.

Pontiggia, M., Derudi, M., Alba, M., Scaioni, M., Rota, R., 2010. Hazardous gas releases in urban areas: Assessment of consequences through CFD modelling. Journal of Hazardous Materials 176, 589 - 596.

Pontiggia, M., Landucci, G., Busini, V., Derudi, M., Alba, M., Scaioni, M., Bonvicini, S., Cozzani, V., Rota, R., 2011. CFD model simulation of LPG dispersion in urban areas. Atmospheric Environment 45, 3913 - 3923.

Raj, P., 2005. Exposure of a liquefied gas container to an external fire. Journal of Hazardous Materials 122, 37-49.

Ramskill, P.K., 1988. A description of the 'engulf' computer codes - codes to model the thermal response of an LPG tank either fully or partially engulfed by fire. Journal of Hazardous Materials 20, 177-196.

Rebec, A., Kolšek, J., Plešec, P., 2016. Fires in storages of LFO: Analysis of hazard of structural collapse of steel-aluminium containers. Journal of Hazardous Materials 306, 367-375.

Reid, R.C., 1979. Possible mechanism for pressurized-liquid tank explosions or bleve's. Science 203, 1263-1265. 
Ren, J.J., Shi, J.Y., Liu, P., Bi, M.S., Jia, K., 2013. Simulation on thermal stratification and de-stratification in liquefied gas tanks. International Journal of Hydrogen Energy 38, 4017-4023.

Reniers, G., Cozzani, V. (Eds.), 2013. 1 - Historical Background and State of the Art on Domino Effect Assessment. Elsevier, Amsterdam.

Roh, S., Son, G., Song, G., Bae, J., 2013. Numerical study of transient natural convection in a pressurized LNG storage tank. Applied Thermal Engineering 52, 209-220.

Saldi, Z.S., Wen, J.X., 2016. Modeling thermal response of polymer composite hydrogen cylinders subjected to external fires. International Journal of Hydrogen Energy, http://dx.doi.org/10.1016/j.ijhydene.2016.06.108.

Salzano, E., Picozzi, B., Vaccaro, S., Ciambelli, P., 2003. Hazard of pressurized tanks involved in fires. Industrial and Engineering Chemistry Research 42, 1804-1812.

Schmidt, J., 2012. Process and Plant Safety: Applying Computational Fluid Dynamics. WILEY-VCH Verlag, Berlin, Germany.

Segu, X., Darbra, R., Vlchez, J., Arnaldos, J., 2014. Methodology for the quantification of toxic dispersions originated in warehouse fires and its application to the QRA in catalonia (spain). Journal of Loss Prevention in the Process Industries 32, 404-414.

Shi, J., Ren, J., Liu, P., Bi, M., 2013. Experimental research on the effects of fluid and heater on thermal stratification of liquefied gas. Experimental Thermal and Fluid Science 50, 29 - 36. 
Siddapureddy, S., Wehrstedt, K.D., Prabhu, S.V., 2016. Heat transfer to bodies engulfed in di-tert-butyl peroxide pool fires - numerical simulations. Journal of Loss Prevention in the Process Industries 44, 204-211.

Sinai, Y.L., Owens, M.P., 1995. Validation of CFD modelling of unconfined pool fires with cross-wind: Flame geometry. Fire Safety Journal 24, 1-34.

Singh, K.D., Gangadharan, P., Chen, D.H., Lou, H.H., Li, X., Richmond, P., 2014. Computational fluid dynamics modeling of laboratory flames and an industrial flare. Journal of the Air and Waste Management Association 64, 1328-1340.

Sun, B., Guo, K., 2013. Lng accident dynamic simulation: Application for hazardous consequence reduction. Journal of Loss Prevention in the Process Industries 26, 1246-1256.

Sun, B., Guo, K., Pareek, V.K., 2015. Dynamic simulation of hazard analysis of radiations from LNG pool fire. Journal of Loss Prevention in the Process Industries 35, 200-210.

Sun, L., Yan, H., Liu, S., Bai, Y., 2017. Load characteristics in process modules of offshore platforms under jet fire: The numerical study. Journal of Loss Prevention in the Process Industries 47, 29-40.

Tu, J., Yeoh, G., Liu, C., 2013. Computational fluid dynamics. A practical approach (2nd edition). Butterworth-Heinemann, Waltham, MA (US).

Van Den Bosh, C.J.H., Weterings, R.A.P.M., 2005. Methods for the calculation of physical effects (yellow book). the Hague (NL): Committee for the Prevention of Disasters . 
Venart, J., 1999. Boiling liquid expanding vapor explosions (BLEVE): Possible failure mechanisms. ASTM Special Technical Publication 1336, 112 134.

Villa, V., Paltrinieri, N., Khan, F., Cozzani, V., 2016. Towards dynamic risk analysis: A review of the risk assessment approach and its limitations in the chemical process industry. Safety Science 89, $77-93$.

Wang, C.J., Wen, J.X., Chen, Z.B., Dembele, S., 2014. Predicting radiative characteristics of hydrogen and hydrogen/methane jet fires using firefoam. International Journal of Hydrogen Energy 39, 20560-20569.

Wang, L., Li, Y., Li, C., Zhao, Z., 2013. CFD investigation of thermal and pressurization performance in lh 2 tank during discharge. Cryogenics 57, $63-73$.

Xin, P., Khan, F., Ahmed, S., 2017. Dynamic hazard identification and scenario mapping using bayesian network. Process Safety and Environmental Protection 105, $143-155$.

Zarei, E., Azadeh, A., Khakzad, N., Aliabadi, M.M., Mohammadfam, I., 2017. Dynamic safety assessment of natural gas stations using bayesian network. Journal of Hazardous Materials 321, 830 - 840.

Zhao, J., Magenes, L., 2016. CFD modeling of jet fires of different configurations, in: 50th Annual Loss Prevention Symposium 2016, LPS 2016 Topical Conference at the 2016 AIChE Spring Meeting and 12th Global Congress on Process Safety, pp. 76-86. 
773 Zheng, J., Ou, K., Bie, H., Xu, P., Zhao, Y., Liu, X., He, Y., 2012. Heat 774 transfer analysis of high-pressure hydrogen storage tanks subjected to lo775 calized fire. International Journal of Hydrogen Energy 37, 13125 - 13131. 776 12th CHEC.

777 Zheng, J., Ou, K., Hua, Z., Zhao, Y., Xu, P., Hu, J., Han, B., 2013. Exper778 imental and numerical investigation of localized fire test for high-pressure 779 hydrogen storage tanks. International Journal of Hydrogen Energy 38, $780 \quad 10963-10970$. 


\section{List of Figures}

$1 \quad$ Conceptual scheme of the problem and methodology . . . . . . 38

2 Overview of the industrial facility considered for the case study. 39

3 Flow chart illustrating the model fore determining the pool

fire radiation. . . . . . . . . . . . . . . . . . 40

$4 \quad$ Incident radiation in $\mathrm{kW} / \mathrm{m}^{2}$ on the tank at different angles. Fire comes from the right, see Figure 1. . . . . . . . . . . . . . 41

5 Dynamic distribution of temperature $(\mathrm{K})$ in the liquid phase under uniform heat flux. . . . . . . . . . . . . . . . . . 42

6 Dynamic flow field in the liquid phase under uniform heat flux. Vectors are colored by axial velocity $(\mathrm{m} / \mathrm{s})$. . . . . . . . . . . 43

[ 7 Dynamic distribution of temperature $(\mathrm{K})$ in the liquid phase under non-uniform heat flux. . . . . . . . . . . . . . . 44

8 Dynamic flow field in the liquid phase under non-uniform heat flux. Vectors are colored by axial velocity $(\mathrm{m} / \mathrm{s}) . \quad \ldots . . . .445$

9 Pressure (a) and evaporation rate (b) as a function of time predicted with uniform and non-uniform heat flux boundary conditions. . . . . . . . . . . . . . . . . . . 46

A.10 Scheme of a titled pool fire . . . . . . . . . . . . . . 57

A.11 Scheme adopted for view factor determination . . . . . . . . . 58

A.12 Section of the subroutine specifying non-uniform boundary conditions. . . . . . . . . . . . . . . 59 


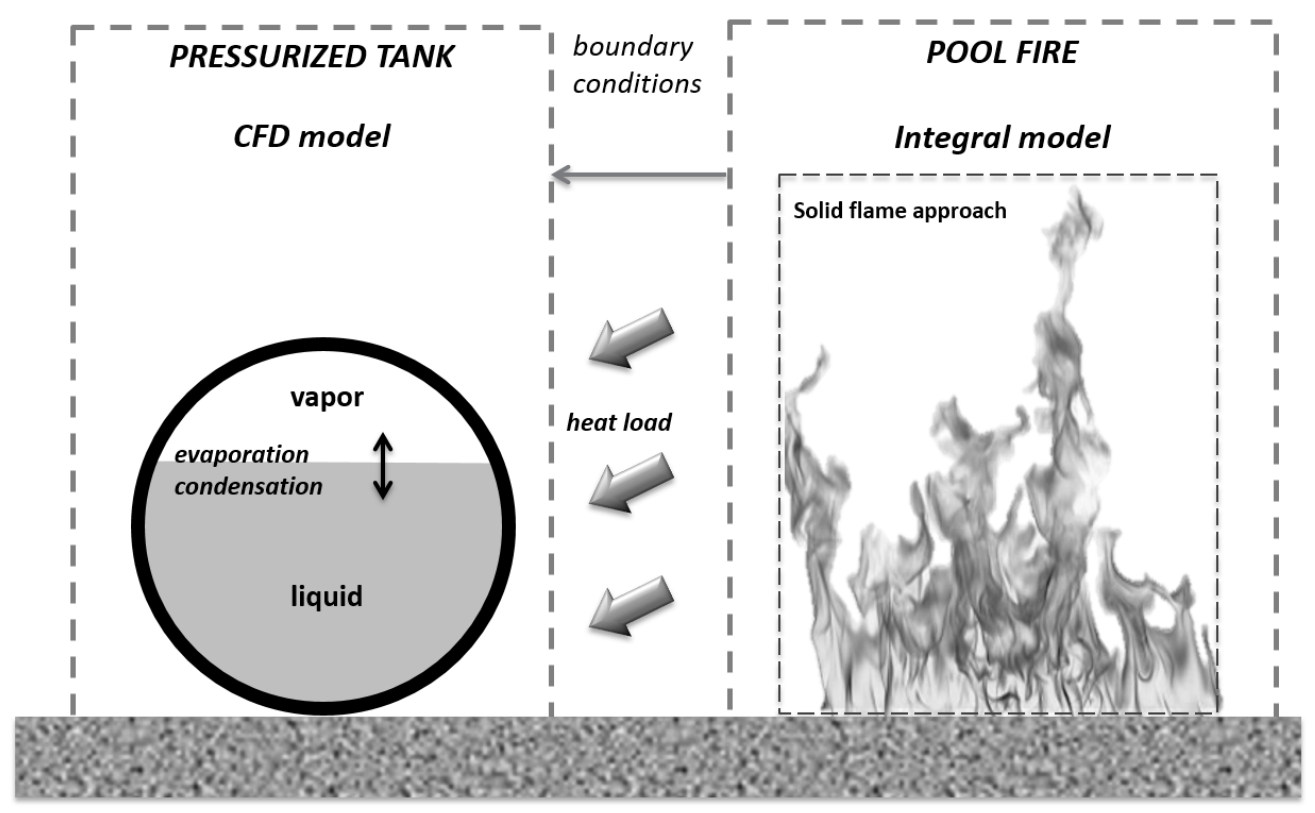

Figure 1: Conceptual scheme of the problem and methodology 


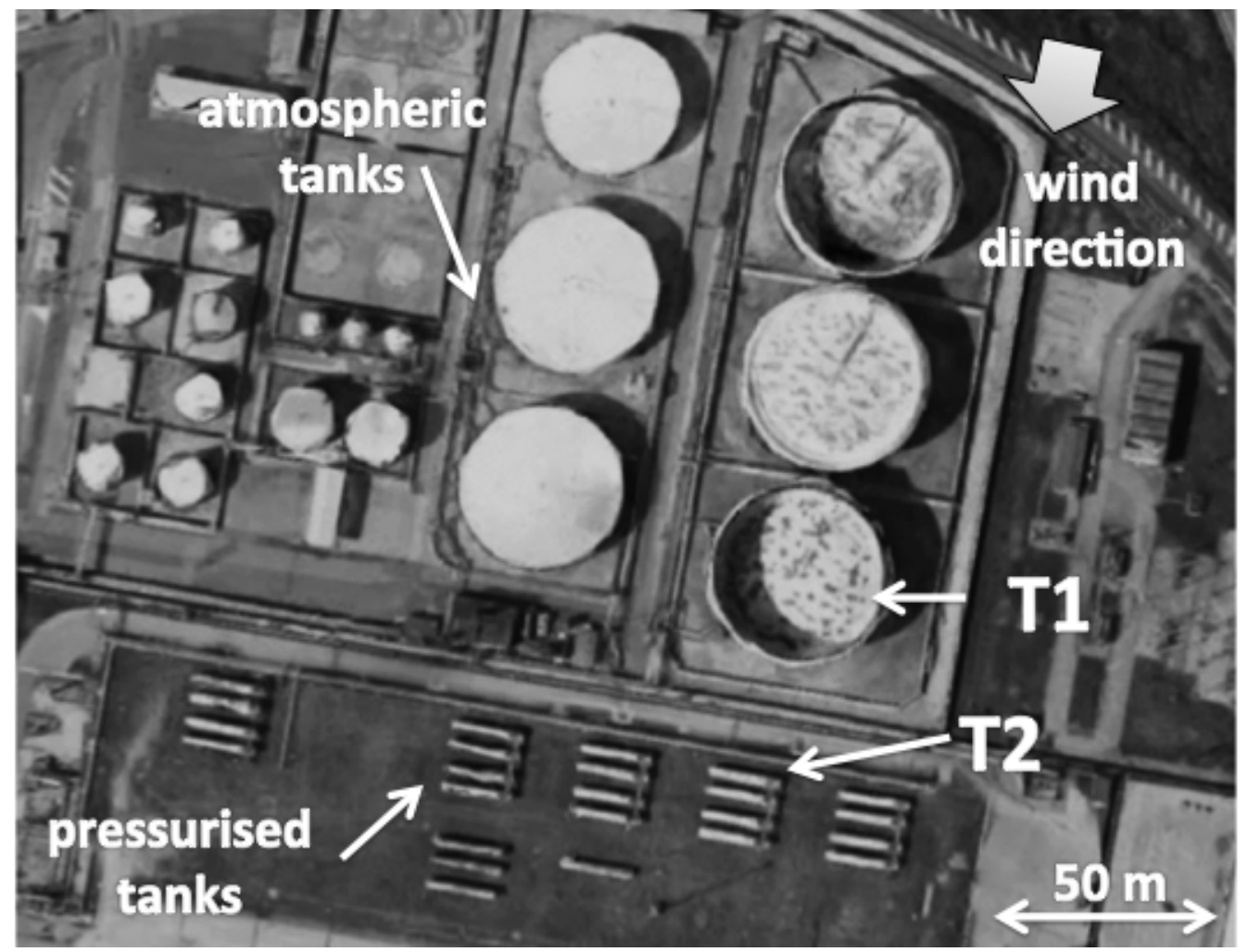

Figure 2: Overview of the industrial facility considered for the case study. 


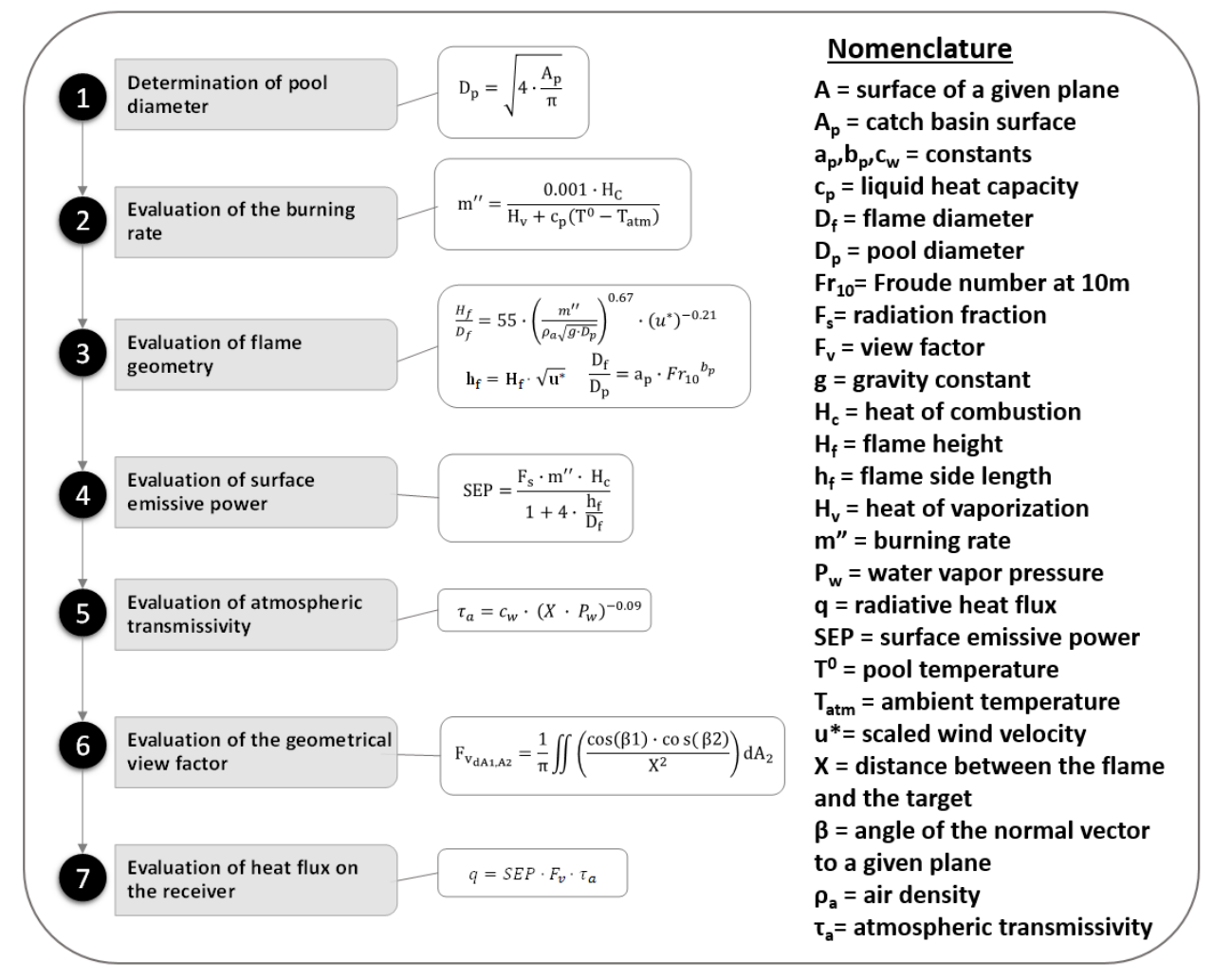

Figure 3: Flow chart illustrating the model fore determining the pool fire radiation. 


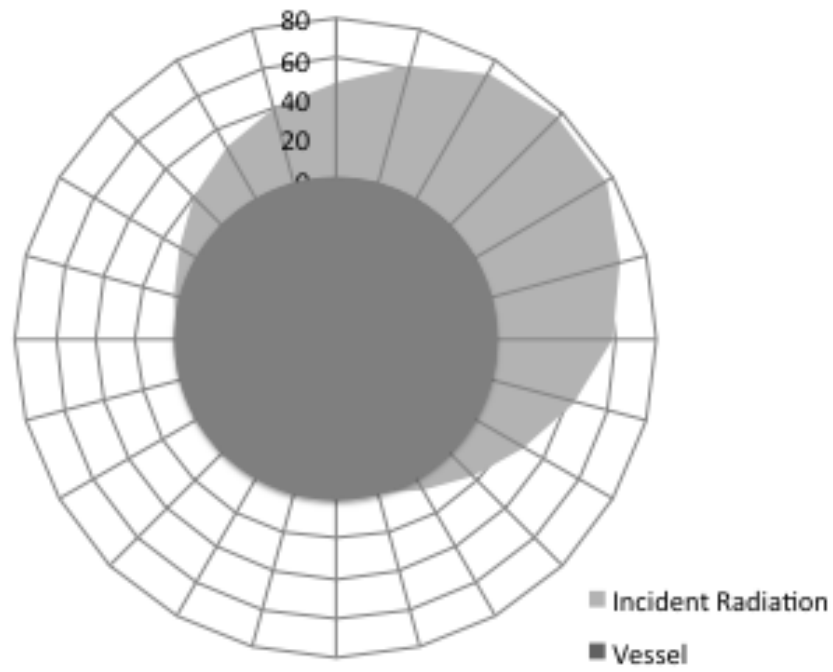

Figure 4: Incident radiation in $\mathrm{kW} / \mathrm{m}^{2}$ on the tank at different angles. Fire comes from the right, see Figure 1 . 


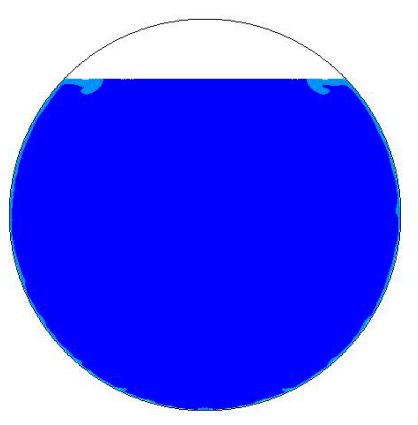

(a) $\tau=5 \mathrm{~s}$

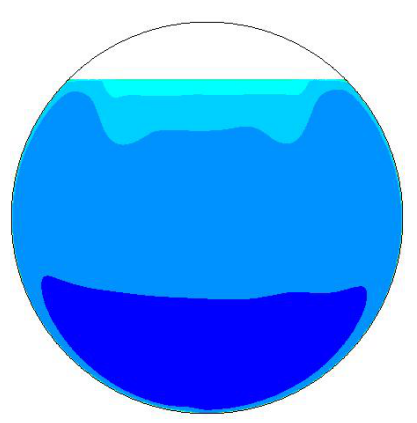

(d) $\tau=100 \mathrm{~s}$

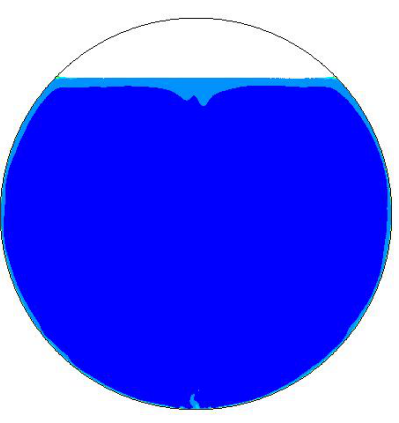

(b) $\tau=15 \mathrm{~s}$

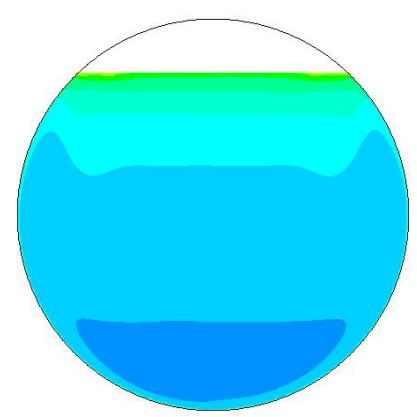

(e) $\tau=200 \mathrm{~s}$

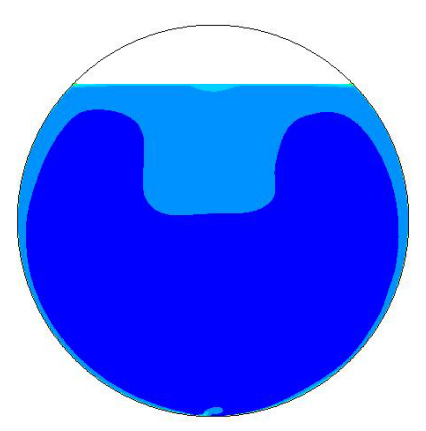

(c) $\tau=50 \mathrm{~s}$

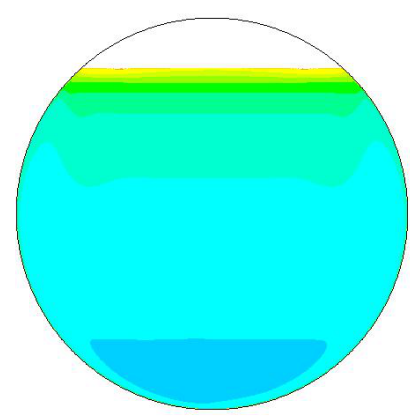

(f) $\tau=$ final

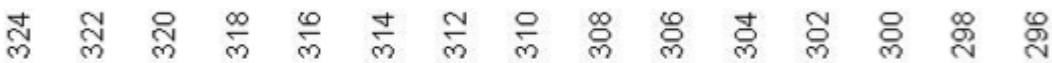

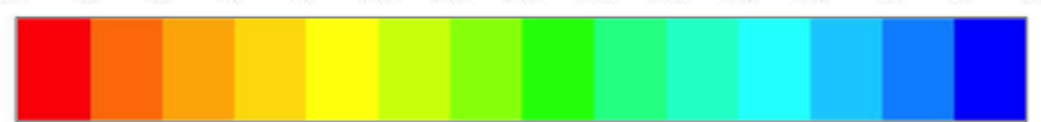

Figure 5: Dynamic distribution of temperature $(\mathrm{K})$ in the liquid phase under uniform heat flux. 


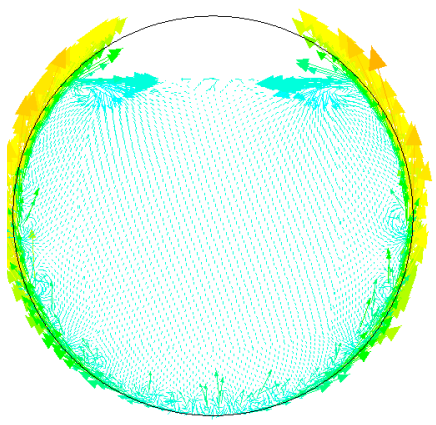

(a) $\tau=5 \mathrm{~s}$

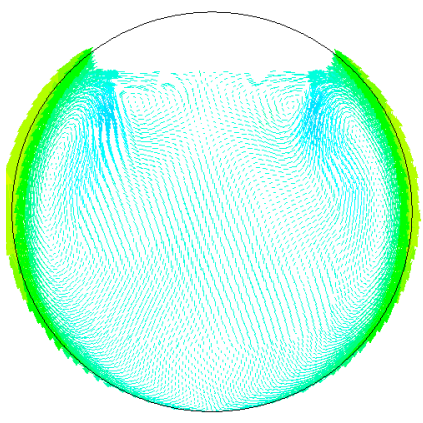

(d) $\tau=100 \mathrm{~s}$

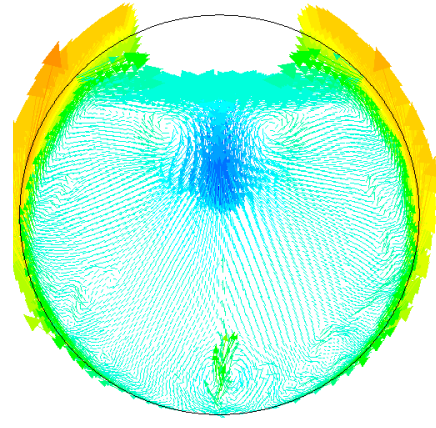

(b) $\tau=15 \mathrm{~s}$

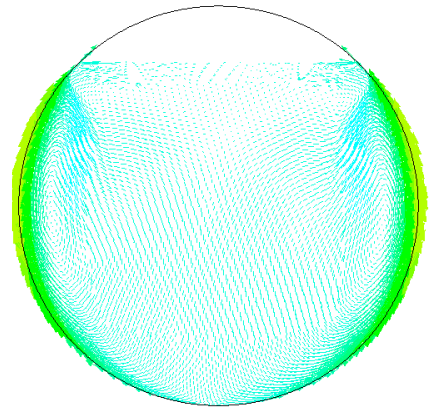

(e) $\tau=200 \mathrm{~s}$

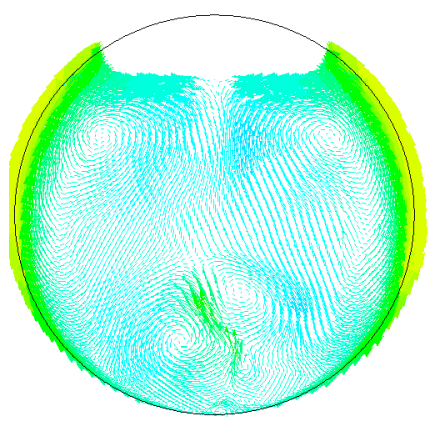

(c) $\tau=50 \mathrm{~s}$

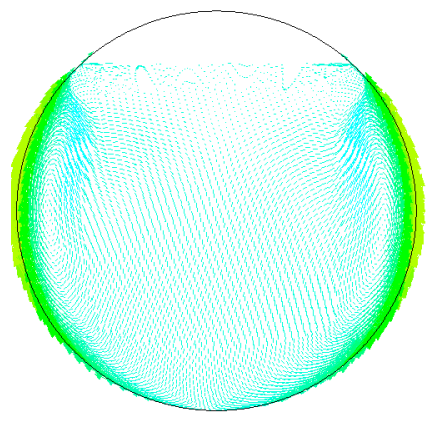

(f) $\tau=$ final

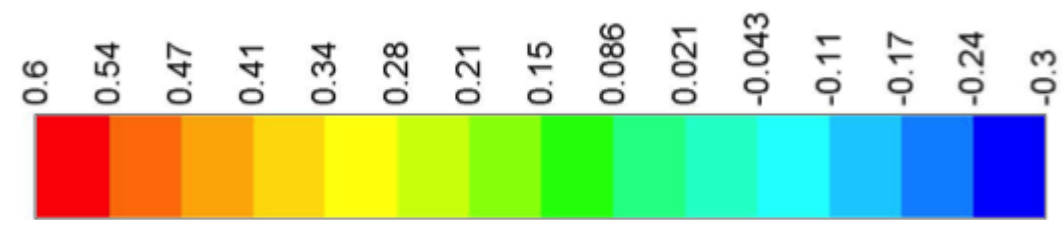

Figure 6: Dynamic flow field in the liquid phase under uniform heat flux. Vectors are colored by axial velocity $(\mathrm{m} / \mathrm{s})$. 


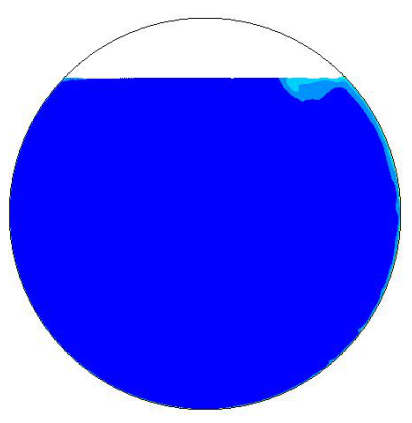

(a) $\tau=5 \mathrm{~s}$

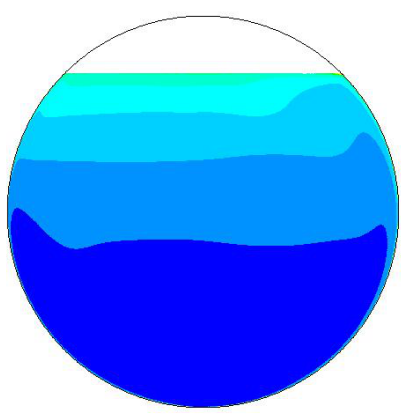

(d) $\tau=100 \mathrm{~s}$

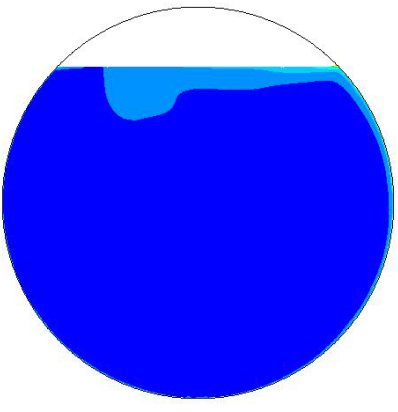

(b) $\tau=15 \mathrm{~s}$

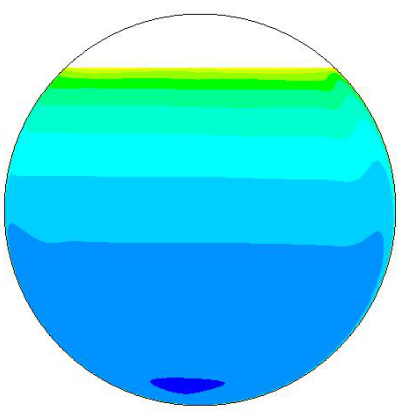

(e) $\tau=200 \mathrm{~s}$

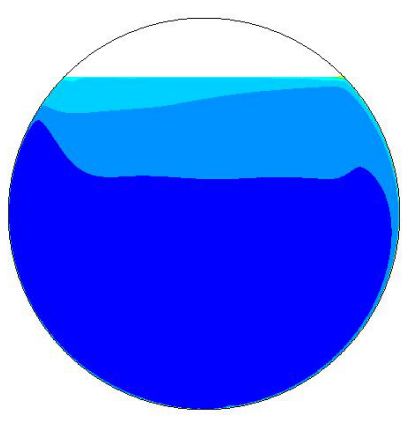

(c) $\tau=50 \mathrm{~s}$

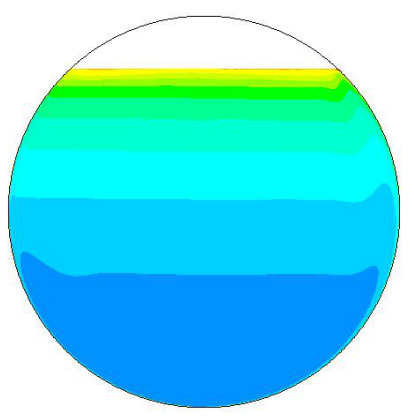

(f) $\tau=$ final

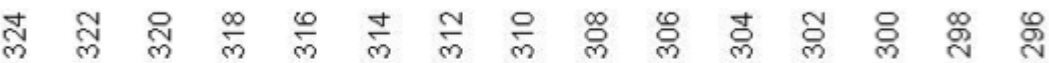

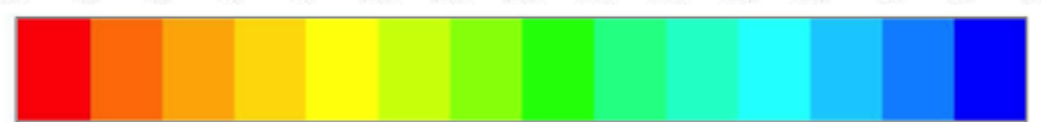

Figure 7: Dynamic distribution of temperature $(\mathrm{K})$ in the liquid phase under non-uniform heat flux. 


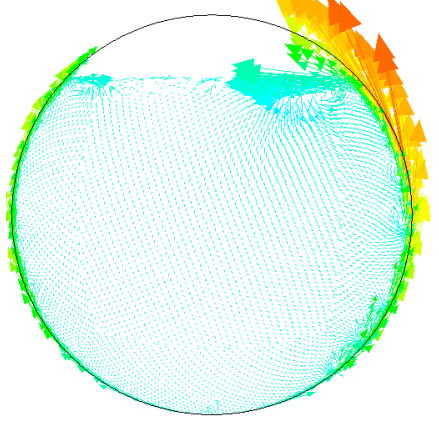

(a) $\tau=5 \mathrm{~s}$

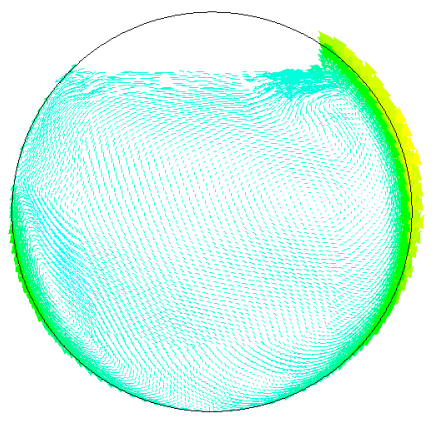

(d) $\tau=100 \mathrm{~s}$

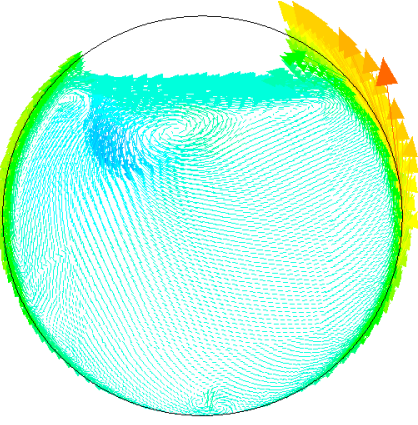

(b) $\tau=15 \mathrm{~s}$

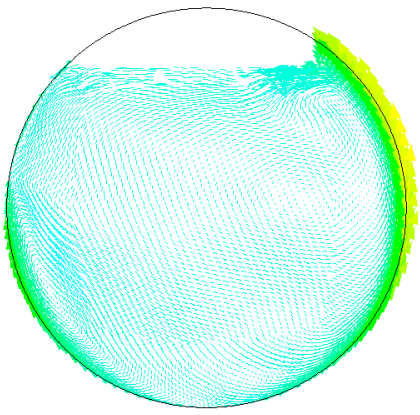

(e) $\tau=200 \mathrm{~s}$

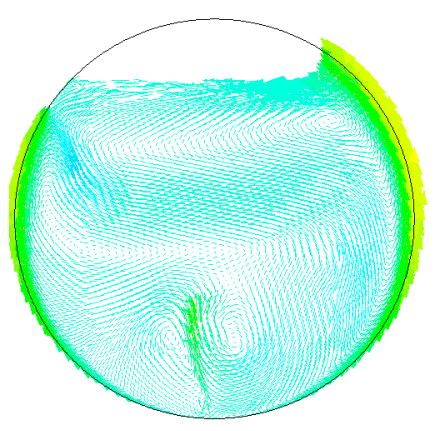

(c) $\tau=50 \mathrm{~s}$

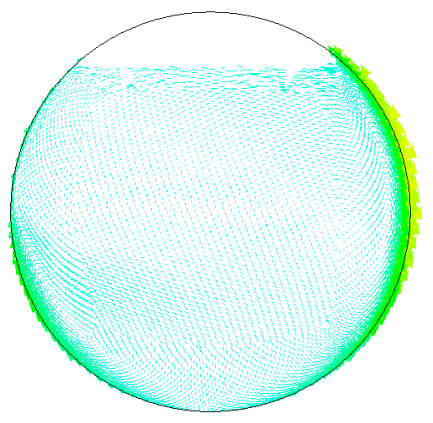

(f) $\tau=$ final

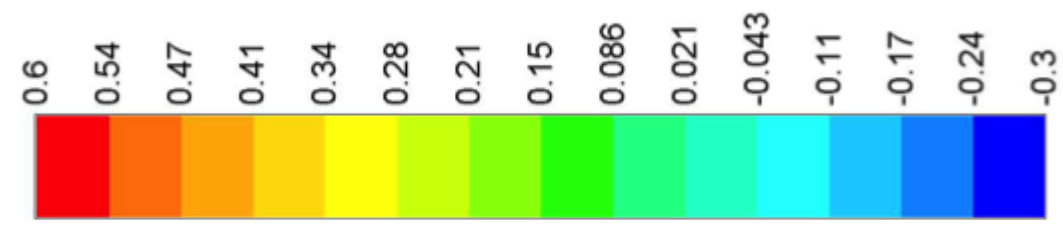

Figure 8: Dynamic flow field in the liquid phase under non-uniform heat flux. Vectors are colored by axial velocity $(\mathrm{m} / \mathrm{s})$. 


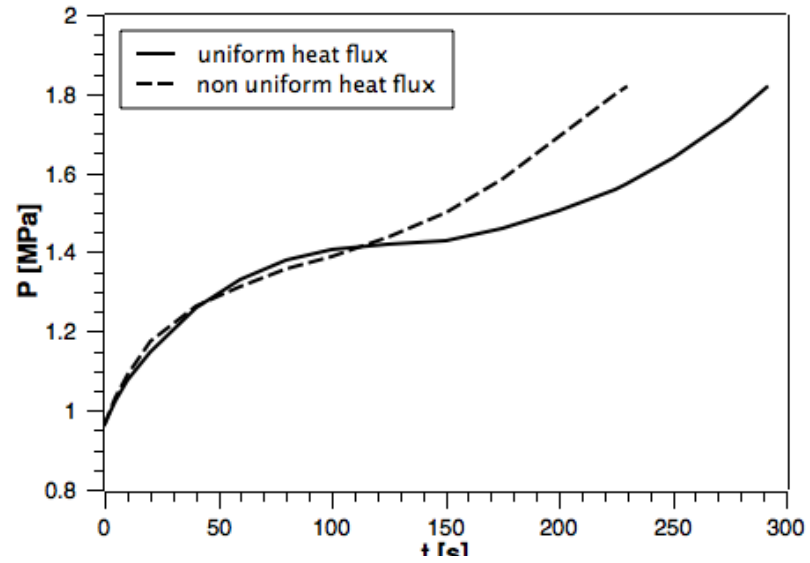

(a)

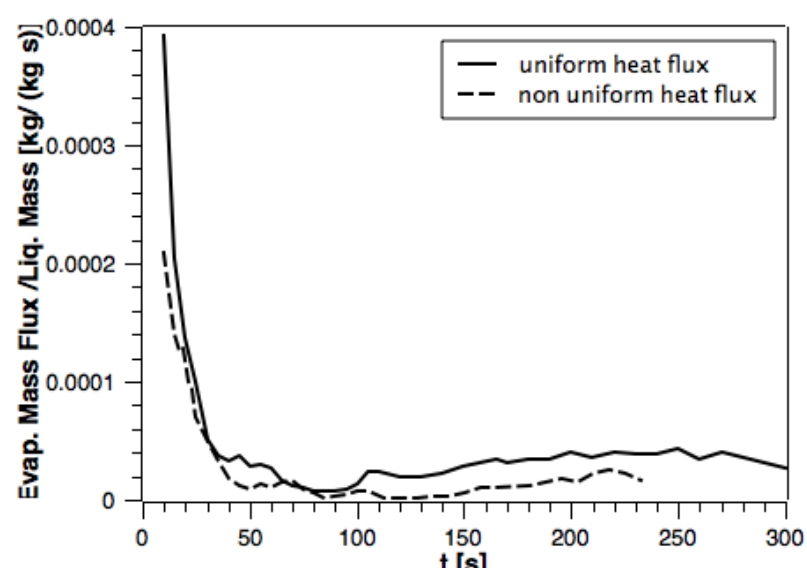

(b)

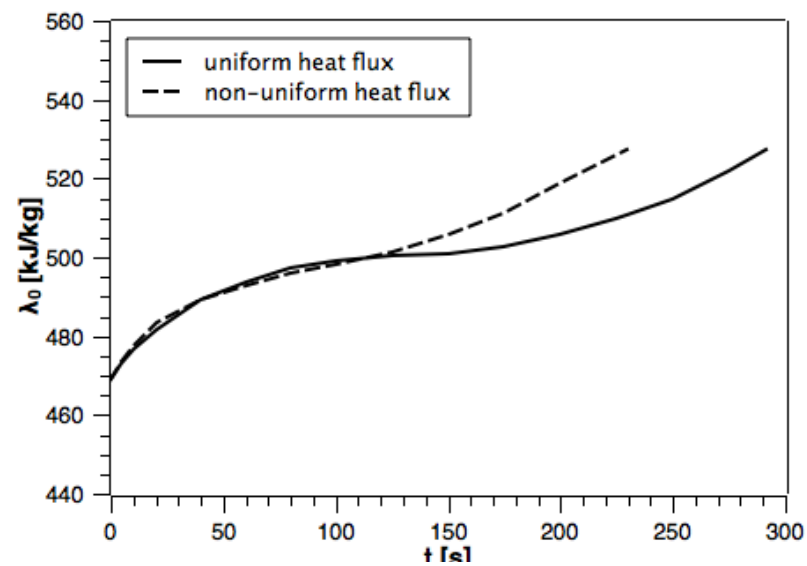

(c)

Figure 9: Pressure (a) and evaporation rate (b) as a function of time predicted with uniform and non-uniform heat flux boundary conditions. 
${ }_{803}$ List of Tables

$804 \quad 1 \quad$ Main features of the tanks considered for the case study. . . . 48

${ }_{805}^{804} \quad$ Correlations used in the CFD model to evaluate propane prop-

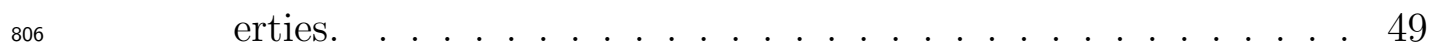

${ }_{807}$ A.3 Physical properties of n-hexane . . . . . . . . . . 61 
Table 1: Main features of the tanks considered for the case study.

\begin{tabular}{c|cc}
\hline Property & Tank T1 & Tank T2 \\
\hline Nominal diameter $(\mathrm{m})$ & 42 & 3.2 \\
Nominal height/length $(\mathrm{m})$ & 5.4 & 19.4 \\
Maximum wall thickness $(\mathrm{mm})$ & 12.5 & 27 \\
Design pressure (barg)* & 0.02 & 17 \\
Nominal volume $\left(\mathrm{m}^{3}\right)$ & 7500 & 150 \\
Stored fluid & n-hexane & propane \\
Filling ratio (-) & 0.7 & 0.9 \\
Inventory (t) & 3439 & 78 \\
Area of the catch basin $\left(\mathrm{m}^{2}\right)$ & 3575 & $18000^{* *}$ \\
\hline *assumed as the release valve set pressure \\
** pressurized tanks share the same catch basin area
\end{tabular}


Table 2: Correlations used in the CFD model to evaluate propane properties.

\begin{tabular}{ccc}
\hline Property & Units & Correlation \\
\hline liquid density $\rho_{L}$ & $\mathrm{~kg} / \mathrm{m}^{3}$ & $\rho_{L}=-24.063+4.9636 T-0.0109 T^{2}$ \\
vapour density $\rho_{V}$ & $\mathrm{~kg} / \mathrm{m}^{3}$ & PengRobinson EOS \\
liquid heat capacity $c_{p, L}$ & $\mathrm{~J} /(\mathrm{kg} \mathrm{K})$ & $c_{p, L}=36309-230.2 T+0.3941 T^{2}$ \\
vapour heat capacity $c_{p, V}$ & $\mathrm{~J} /(\mathrm{kgK})$ & $c_{p, V}=345.58+4.4019 T$ \\
liquid thermal conductivity $\kappa_{L}$ & $\mathrm{~W} /(\mathrm{mK})$ & $\kappa_{L}=0.26755-6.6 \cdot 10^{-4} T+2.77 \cdot 10^{-7} T^{2}$ \\
vapour thermal conductivity $\kappa_{V}$ & $\mathrm{~W} /(\mathrm{mK})$ & $\kappa_{V}=-0.0088+6.0 \cdot 10^{-5} T+1.0 \cdot 10^{-7} T^{2}$ \\
liquid dynamic viscosity $\mu_{L}$ & $\mathrm{~Pa} \mathrm{~s}$ & $\mu_{L}=709137 T^{-3.986}$ \\
vapour dynamic viscosity $\mu_{V}$ & $\mathrm{~Pa} \mathrm{~s}$ & $\mu_{V}=4.9054 \cdot 10^{-8} T^{0.90125}$ \\
\hline
\end{tabular}




\section{Appendix A. Procedure for the evaluation of pool fire heat radia- tion effects}

The procedure for the consequence assessment of pool fire radiation is well known in the literature and is summarized in the following. In this work, the application of the procedure allowed obtaining the boundary conditions for the CFD simulation described in Section 5. For the analysis of the case study, a crude oil pool fire (assimilated as pure n-hexane) was simulated. The physical properties of n-hexane are reported in Table A.3. More details on integral models adopted for pool fire simulation are extensively reported elsewhere Mannan (2012) Van Den Bosh and Weterings (2005).

[Table 3 about here.]

\section{Appendix A.1. Determination of pool diameter}

The first step is aimed at determining the liquid pool equivalent diameter $\left(D_{p}\right)$, since the liquid hydrocarbon from tank T1 is spilled into a rectangular catch basin, covering its entire surface (see Figure 2). The following relationship is adopted:

$$
D_{p}=\sqrt{\frac{4}{\pi A_{p}}}
$$

where $A_{p}$ is the area of the catch basin (see Table 1 ).

\section{Appendix A.2. Evaluation of the burning rate}

The burning rate $\left(m^{\prime \prime}\right.$, in $\left.\mathrm{kg} \mathrm{s}^{-1} \mathrm{~m}^{-2}\right)$ is defined as the rate of evaporation of material per unit surface on the pool. For large pool fires (e.g., $D_{p}>1 \mathrm{~m}$ ), $m^{\prime \prime}$ depends only on the type of substance and may be evaluated as follows:

$$
m^{\prime \prime}=\frac{0.001 \cdot H_{C}}{H_{V}+c_{p}\left(T^{0}-T_{a t m}\right)}
$$


where $H_{C}$ and $H_{V}$ (in $\mathrm{J} / \mathrm{kg}$ ) are respectively the heat of combustion and of vaporization of the substance at the pool temperature $T^{0}$ (see Table A.3); $c_{p}$ is the average liquid heat capacity and $T_{a t m}$ is the ambient temperature. It is worth mentioning that, for an evaporating pool, such as in the present case, pool temperature is equal to the atmospheric temperature (hence, $T^{0}-T_{a t m}=$ $0)$.

\section{Appendix A.3. Evaluation of flame geometry}

In the so called solid flame approach, the flame is simulated as a solid of a given geometry featuring an average emissivity. In the present work a tilted cylindrical shape was determined for the flame, considering the burning rate and the effect of wind on the flame structure (see Figure A.10).

[Figure 10 about here.]

Firstly, the scaled wind velocity $u^{*}$ is evaluated as follows:

$$
u^{*}=\frac{u_{w}}{\left(\frac{g m^{\prime \prime} D_{p}}{\rho_{a}}\right)^{0.33}}
$$

where $u_{w}$ is the wind velocity at a height of $10 \mathrm{~m}, \rho_{a}$ is the air density $\left(=1.25 \mathrm{~kg} \mathrm{~m}^{-3}\right)$ and $g$ is the gravitational acceleration $\left(=9.81 \mathrm{~m} \mathrm{~s}^{-2}\right)$. The scaled velocity allows accounting for wind tilting effects in the pool fire, which geometrical parameters were estimated adopting the following semi-empirical correlation:

$$
\frac{H_{f}}{D_{f}}=55\left(\frac{m^{\prime \prime}}{\rho_{a} \sqrt{g D_{p}}}\right)^{0.67}\left(u^{*}\right)^{-0.21}
$$


where $H_{f}(\mathrm{~m})$ is the flame height and $D_{f}$ is the flame diameter. The flame side length $h_{f}$ (see Figure A.10) is then determined as a function of the flame height and scaled wind velocity:

$$
h_{f}=\frac{H_{f}}{\cos (\theta)}=H_{f} \sqrt{u^{*}}
$$

where $\theta$ is the tilted angle (see Figure A.10). Finally, the flame diameter $\left(D_{f}\right.$, in $\left.\mathrm{m}\right)$ was obtained applying the following relationship, accounting for the displacement due to wind:

$$
\left.\frac{D_{f}}{D_{p}}=a_{p}\left(F r_{10}\right)\right)^{b_{p}}
$$

in which $F r_{10}$ is the Froude number at $10 \mathrm{~m}$ defined as follows:

$$
F r_{10}=\frac{u_{w}^{2}}{g D_{p}}
$$

The coefficients $a_{p}$ and $b_{p}$ both depend on the flame geometry type; for cylindrically shaped flames $a_{p}=1.5$ and $b_{p}=0.069$ Van Den Bosh and Weterings (2005)

Appendix A.4. Evaluation of surface emissive power (SEP)

Once having determined the flame shape, the surface emissive power $(S E P)$ can be estimated. SEP indicates the heat radiated outwards per unit surface are of the flame. The following correlation was adopted to determine the maximum value of $S E P$, without accounting for the effect of soot, thus obtaining a conservative evaluation Van Den Bosh and Weterings (2005):

$$
S E P=\frac{F_{s} m^{\prime \prime} H_{C}}{1+4 \frac{h_{f}}{D_{f}}}
$$


in which $F_{s}$ indicates radiation fraction (the amount of heat generated by the flame which is transferred by radiation).

\section{Appendix A.5. Evaluation of atmospheric transmissivity}

The atmospheric transmissivity $\left(\tau_{a}\right)$ accounts for the fact that the emitted radiation is partly absorbed by the air present between the flame and the target receiver. The transmissivity depends on the absorbing properties of the components of the ambient air in relationship to the emission spectrum of the fire. Neglecting the presence of carbon dioxide in the atmospheric air, water vapor was considered as the main absorbing component within the wave length area of the heat radiation, thus the following approximating expression was adopted (Mannan (2012)):

$$
\tau_{a}=c_{w}\left(X P_{w}\right)^{-0.09}
$$

in which $c_{w}$ is a constant $\left(=2.02(\mathrm{~N} / \mathrm{m})^{0.09}\right)$ and the following conditions is verified:

$$
10^{4}<X P_{w}<10^{6} \mathrm{~N} / \mathrm{m}
$$

where $X$ is the distance of the receiver (see Figure A.10) and $P_{w}$ is the partial pressure of water vapour in the atmospheric air (thus, function of the relative humidity).

\section{Appendix A.6. Evaluation of the geometrical view factor}

The geometrical view factor $\left(F_{v}\right)$ is the ratio between the received and the emitted radiation power per unit surface. The factor is determined by the flame dimensions and shape, and by the relative position and orientation 
of the receiving object. Considering the representation reported in Figure A.11, the geometrical view factor is defined as follows:

$$
F_{v_{d A 1, d A 2}}=\frac{1}{\pi} \iint\left(\frac{\cos \left(\beta_{1}\right) \cos \left(\beta_{2}\right)}{X^{2}}\right) d A_{2}
$$

where $X$ is the distance between the centers of $d A_{1}$ and $d A_{2}, \beta_{1}$ is the angle of the normal vector to plane $d A_{1}$ and the line connecting $d A_{1}$ and $d A_{2}$ and $\beta_{2}$ is the angle of the vector to plane $d A_{2}$ and the line connecting $d A_{1}$ and $d A_{2}$.

Typically, simple flame shapes are taken for the calculations such as sphere, cylinder and flat plate. In the present study, the view factor of a cylinder may be used. The approach developed by Raj Raj (2005) was adopted in the present study to estimate the view factor on the target tank. The reader is referred to Raj (2005) for more details on the procedure. Practically the tank surface was divided into 16 sectors and, for each of them, the view factor $F_{v_{i}}$ from the cylinder (i.e., the pool fire) to the sector centroid was estimated.

\section{Appendix A.7. Evaluation of heat flux on the receiver}

Finally, the heat flux $q_{i}\left(\mathrm{~W} \mathrm{~m}^{-2}\right)$ from the pool fire on the tank surface $\mathrm{i}$-th sector is evaluated through the radiative heat transfer equation Modest (2003)

$$
q_{i}=S E P \cdot F_{v_{i}} \cdot \tau_{a_{i}}
$$


The procedure described above allowed obtaining the incoming heat flux distribution on the external surface of the tank, at 16 discrete locations. Subsequently the heat flux was linearized between such locations, resulting in the heat flux distribution shown in Figure 4. Such distribution was set as boundary condition for the CFD model through a $\mathrm{C}++$ User Defined Functions that basically checks the $(x, y)$ coordinates of the location in the boundary to determine the angular coordinate and thus associate the corresponding heat flux. A section of the subroutine is reported in Figure A.12

[Figure 12 about here.] 
${ }_{912}$ List of Figures 


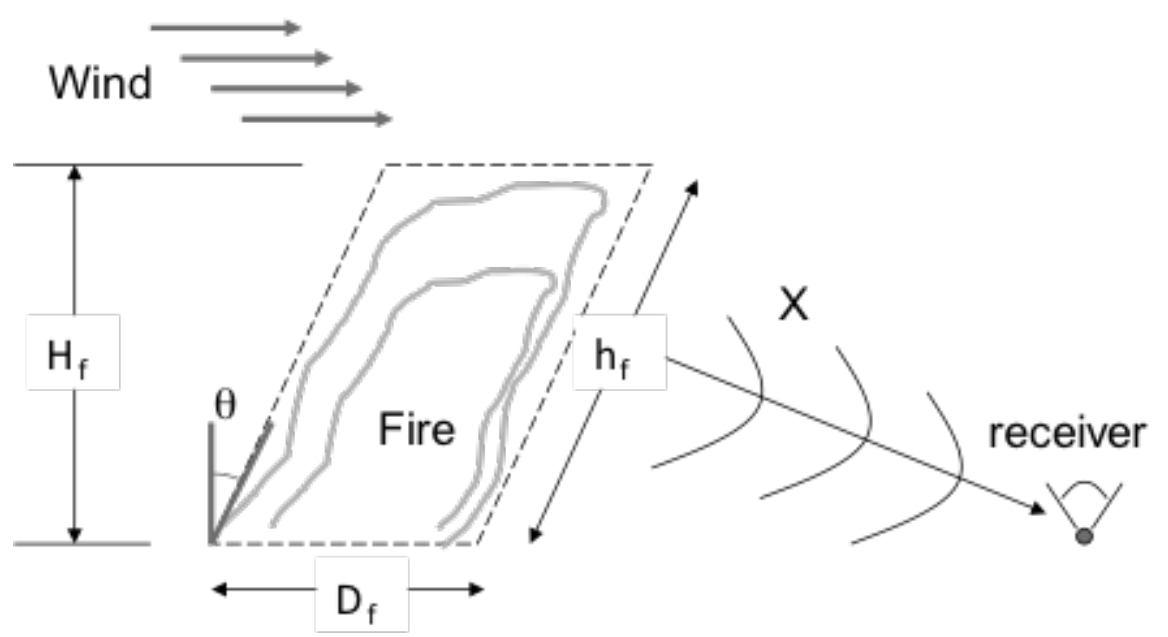

Figure A.10: Scheme of a titled pool fire 


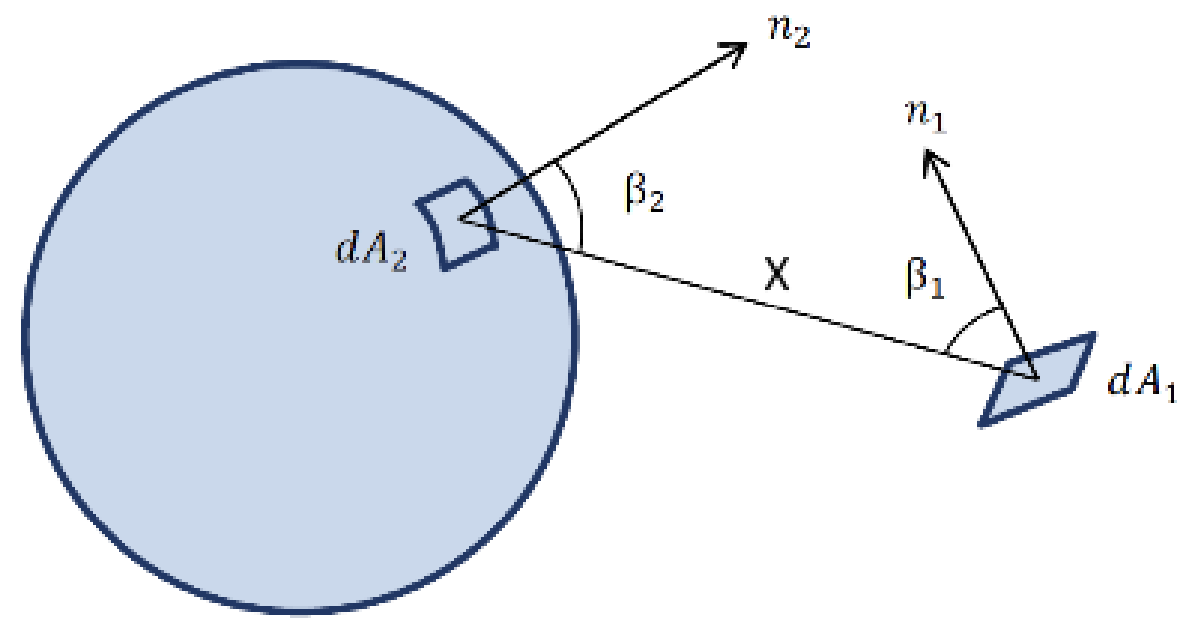

Figure A.11: Scheme adopted for view factor determination 


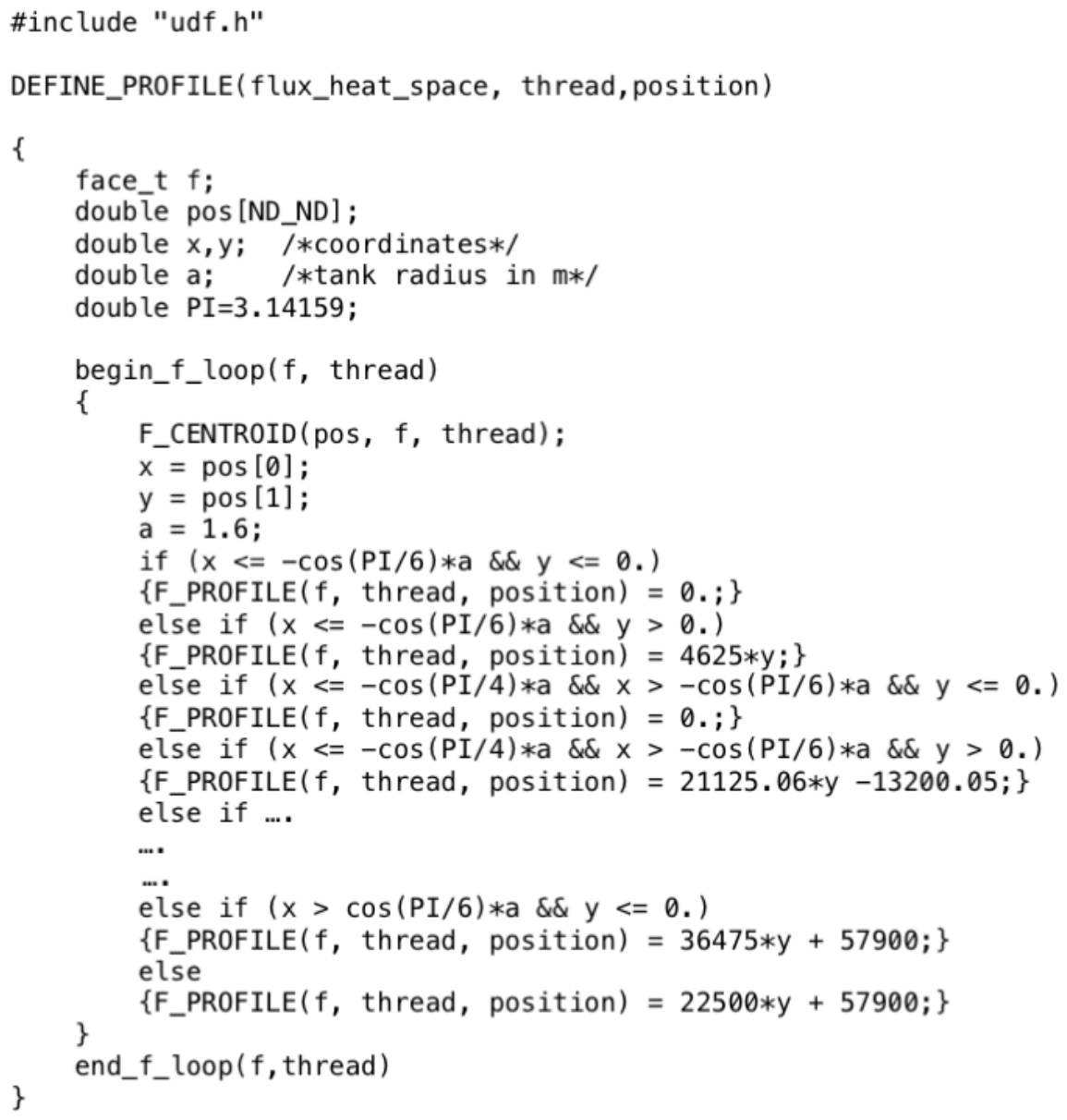

Figure A.12: Section of the subroutine specifying non-uniform boundary conditions. 
${ }_{913}$ List of Tables 
Table A.3: Physical properties of n-hexane

\begin{tabular}{cccc}
\hline Property & Units & Value & Reference \\
\hline Liquid density $\rho_{L}$ & $\mathrm{~kg} \mathrm{~m}^{-3}$ & 655 & Liley et al. $(1999)$ \\
Heat of vaporization $H_{V}$ & $\mathrm{MJ} \mathrm{kg}^{-1}$ & 0.37 & Green and Perry $(2008)$ \\
Heat of combustion $H_{C}$ & $\mathrm{MJ} \mathrm{kg}^{-1}$ & 45.1 & Green and Perry \\
Radiation fraction $F_{s}$ & - & $0.3^{*}$ & Mannan (2012) \\
\hline
\end{tabular}

* conservative value, assumed for the present case study 